\title{
Reduction or discontinuation of antipsychotics for challenging behaviour in adults with intellectual disability: a systematic review
}

Rory Sheehan MSc, Academic clinical fellow in psychiatry of intellectual disability, Division of Psychiatry, University College London, $6^{\text {th }}$ floor, Maple House, 149 Tottenham Court Road, London W1T 7NF

Angela Hassiotis PhD, Professor (full) of psychiatry of intellectual disability, Division of Psychiatry, University College London, $6^{\text {th }}$ floor, Maple House, 149 Tottenham Court Road, London W1T 7NF

\section{Summary}

The use of antipsychotics to manage challenging behaviour in adults with intellectual disability is widespread but controversial and lacking in evidence. There is a perception that antipsychotics used in this context can be reduced or discontinued and this has been a major focus of recent national policy. However, such an intervention risks harm as well as having potential benefits. We reviewed the available evidence and found that antipsychotics can be reduced or discontinued in a significant proportion of adults who use them for challenging behaviour, though not always without adverse reactions. There is a group who display behavioural deterioration on antipsychotic reduction that prevents discontinuation; predictors of poor response could not be reliably identified. Given the relative lack of data and methodological limitations of the available studies, we cannot draw firm conclusions to inform a population level approach to this issue. Antipsychotic medication used for behaviour should be reviewed regularly and an individualised approach taken to treatment. 


\section{Introduction}

Intellectual disability (ID) is a lifelong condition of impaired cognitive function and deficit in adaptive skills. ${ }^{1}$ Antipsychotic medication is often prescribed to adults with ID to manage challenging behaviour in the absence of severe mental illness. ${ }^{2,3}$ Challenging behaviour is a non-specific term used to describe any behaviour that may threaten the physical safety of a person with ID or those around them, or that is likely to limit access to ordinary community facilities. ${ }^{4}$ It includes presentations such as aggression, self-injury, and property destruction. The prevalence of challenging behaviour in those with ID is typically quoted as $10-15 \%, 5,6$ although that this might be an underestimate. ${ }^{2,7}$ Interventions aimed at reducing the frequency or degree of challenging behaviour must recognise the array of biological, psychological, and social factors that can underlie the development and maintenance of behaviour disturbance. ${ }^{8}$ There is very limited evidence that antipsychotics are effective in reducing challenging behaviour in adults with ID. ${ }^{9,10}$ The NICE guideline on behaviour that challenges recommends a stepped approach to assessment and a central role for psychosocial strategies in management, with antipsychotic medication being used only in certain circumstances and continued only when benefit is clearly demonstrated (panel 1). ${ }^{11}$

There has been longstanding criticism of the use, and perceived over-use of antipsychotic medication in people with ID. ${ }^{12,13}$ Professionals and care providers are under close scrutiny following the exposure of systemic abuse of people with ID and complex challenging behaviours at Winterbourne View Hospital, and the prescription of psychotropic medication to people with ID has achieved widespread coverage in the lay and specialist media. ${ }^{14,15}$ Transforming Care, the UK Government response to the scandal at Winterbourne View, restated concerns about the inappropriate use of psychotropic medication in this group. ${ }^{16}$ These concerns were substantiated by two studies of psychotropic prescribing to people with ID in UK primary care. ${ }^{2,17}$ NHS England have issued a 'Call to Action,' (https://www.england.nhs.uk/2015/07/urgent-pledge/), a national drive to reduce antipsychotic prescription rates in people with ID.

Challenging behaviour often persists and those who are prescribed antipsychotic medication tend to remain on it for long periods. ${ }^{18,19}$ Reasons might include; favourable drug response; lack of efficacy or availability of alternative (psychosocial) treatments; infrequent or ineffectual medication review; and lack of professional or caregiver confidence in making medication changes for fear of the consequence.

Long-term antipsychotic use is not without risks and adverse effects associated with antipsychotic drugs include movement (extra-pyramidal) side-effects, autonomic disturbance, and endocrine and metabolic disorders. ${ }^{20}$ Some can cause sedation and those with a high-degree of anti-cholinergic activity might impair cognition, especially when used in combination with other anti-cholinergic agents. ${ }^{21,22}$ People with ID are often considered at greater risk of developing such side-effects ${ }^{23}$ although there has been relatively little research on the side-effect profile of psychotropic drugs specifically in people with ID and few studies directly compare side-effect rates in people with and without ID.

It is desirable to reduce antipsychotic medication where possible. There is evidence of the effect of antipsychotic discontinuation in adults with average intelligence who take 
antipsychotics for severe mental illness ${ }^{24,25}$ and older adults prescribed antipsychotics for neuropsychiatric symptoms in dementia. ${ }^{26,27}$ Antipsychotic discontinuation in children with autism spectrum disorders who take antipsychotics for behaviour disorder has also been studied, although primarily with the intention of testing the efficacy of long-term antipsychotic use rather than investigating the consequences of planned reduction. ${ }^{28-30}$ As yet there has been no thorough review of the effect of antipsychotic discontinuation in those with ID and the focus of existing discontinuation studies, the participants included, and outcomes measured mean that results might not generalize to those with ID who take antipsychotics.

We conducted a systematic review of the evidence concerning the outcome of reduction or discontinuation of long-term antipsychotic medication used for management of challenging behaviour in adults with ID.

[Panel 1 near here]

\section{Methods}

Electronic databases (Medline, EMBASE, PsycINFO, Cochrane, CINAHL Plus) were searched for relevant articles published in any language between $1^{\text {st }}$ January 1990 and $1^{\text {st }}$ March 2016. Search terms for 'intellectual disability', 'antipsychotic medication' and 'reduction/discontinuation' and their synonyms were combined, with relevant MeSH terms also included (appendix A). Reference lists of included studies were checked and their citations were tracked using the Science Citation Index Expanded to supplement the original search. The review protocol was registered with PROSPERO (2015:CRD42015019917).

We included studies published in peer-reviewed journals and all study designs, including individual case studies, but excluded non-peer reviewed articles including letters, meeting abstracts, and dissertations.

Adults ( $>18$ years) with any degree of ID of any aetiology were included. ID was authordefined and expected to conform to ICD/DSM criteria. Participants could have any physical or psychiatric co-morbidity, although those studies where a significant number had psychotic disorders were excluded. Studies conducted in community or institutional settings were included.

Participants must have been taking an antipsychotic regularly for at least 12 weeks before the intervention. Studies reporting reduction or discontinuation of either first- and secondgeneration antipsychotics were included. The antipsychotic must have been used primarily to manage challenging behaviour, rather than to treat mental illness. Challenging behaviour was author-defined.

The reduction or discontinuation of antipsychotic medication must have been the main intervention. Reduction was defined as a sustained change in antipsychotic to a lower dose and discontinuation as the complete cessation of antipsychotic medication. Any schedule of reduction or discontinuation was permitted. Simultaneous interventions, including 
adjustment of other classes of medication and psychotherapeutic interventions, were acceptable but studies that report the substitution of one antipsychotic for another were not included.

The primary outcome was the proportion of participants achieving dose reduction or discontinuation without drop-out or reinstatement of the antipsychotic. Studies that report average dose changes or where change in antipsychotic use could not be differentiated from change in other psychotropic drugs were excluded.

Secondary outcomes measures included change in behaviour, physical health, mental health, cognitive or adaptive functioning, and quality of life in those who reduced or discontinued antipsychotic medication.

All citations were imported into an EndNote library. Duplicates were removed in a two-stage process using the software function and then manually by checking titles. The titles of the remaining citations were screened against the inclusion criteria. Abstracts of the remaining citations were reviewed allowing the exclusion of further studies. When the abstract indicated the paper potentially met inclusion criteria, the full text was reviewed.

Included studies were categorised according to the hierarchy published by the Centre for Evidence-Based Medicine. ${ }^{31}$ A separate evaluation of the quality of each study was made focusing on limitations and biases.

\section{Results}

\section{Study characteristics}

The initial search yielded a total of 1,018 citations and of these twenty-one studies met inclusion criteria (figure 1). Included studies are summarised in table 1 . Studies excluded after full-text review are listed in appendix B.

[Figure 1 near here]

We found one (open) RCT, the results of which are reported in two papers; ${ }^{32,33}$ one caseseries $^{34}$; one single-case report. ${ }^{35}$ The remainder of studies were observational studies, some of which included control groups. ${ }^{36-39}$

Fifteen studies were conducted in the USA. Five European studies were included and one from Australasia. Thirteen studies included only participants living in institutions, two studies included only those living in community settings, five studies report on participants living in a range of settings, and in one study the living arrangements of participants are not reported.

Studies reported the outcome of antipsychotic discontinuation or reduction in 1,027 participants in total. Discontinuation practices included dose-reduction programmes and that 
were under clinician control. In five studies reduction/discontinuation of antipsychotics was according to formal research protocol.

Details of participants are incompletely reported in several studies. Mean age of participants in studies ranged from 24 to 50 years, with the one case report describing outcome of antipsychotic discontinuation in a 74 year old. There was a predominance of men (approximately $2 / 3$ of those undergoing antipsychotic reduction and discontinuation) and just over $80 \%$ had severe-profound ID. Participants were prescribed antipsychotics for challenging behaviour; in almost all cases the nature of the challenging behaviour was not given. A minority in each study had diagnosed co-morbid mental illness. In studies where indication for antipsychotic prescription was not clearly given, the authors clearly allude to challenging behaviour. Most of the antipsychotics were first generation agents.

\section{Outcomes of reduction or discontinuation of antipsychotic medication used for behaviour}

\section{Success of attempts to reduce or discontinue antipsychotic medication}

Ten studies describe the outcome of reduction or discontinuation of antipsychotic medication as the proportion of the intervention group who were maintained on a lower dose or achieved drug discontinuation at follow-up (ranging from 3 months to over 10 years). ${ }^{32,38,40-47}$ The proportion of participants maintained on a reduced dose was between $19 \%$ and $83 \%$, discontinuation of antipsychotics ranged from $4 \%$ to $74 \%$, the proportion unsuccessful in attempts to reduce or discontinue antipsychotics was between $0 \%$ and $96 \%$ (table 2). In several cases, reporting of the study is such that it is not possible to distinguish three groups accurately. Due to the study designs we are unable to obtain a summary measure of the successful reduction or discontinuation of antipsychotics, but taken together, these studies have value in providing broad estimates of rates of reduction or discontinuation that might be achieved in a clinical setting.

[Table 2 near here]

\section{Effect of reduction or discontinuation of antipsychotics on behaviour}

Six studies report the effect of antipsychotic reduction or discontinuation on participant behaviour. ${ }^{32,39,43,44,47,48}$ Behavioural outcome measures ranged from validated instruments to colloquial reports (Appendix C).

[Table 3 near here]

Ahmed and colleagues found no difference in challenging behaviour in the group who discontinued or reduced antipsychotic medication by $\geq 50 \%$ and the control group who underwent no medication change $\left(p>0 \cdot 05\right.$, data not given). ${ }^{32}$ They also report behaviour outcomes of the 'failure' group, that is, those who were randomised to the drug reduction arm but who did not discontinue or significantly reduce dose. This group did not demonstrate worsening of overall behaviour and the decision to arrest dose reduction or reinstate medication was found to be related to setting rather than individual variables, including 
having fewer full-time and senior staff, lower levels of staff training, and more restrictive environmental features.

deKuijper examined baseline and follow-up differences (12 weeks after planned discontinuation) in carer rated total Aberrant Behaviour Checklist ( $A B C)$ score in their cohort. ${ }^{47}$ In the group that completed antipsychotic discontinuation, the mean total $A B C$ score reduced from 47 ( $s d 27$ ) to 37 ( $s d 29)(p=0.03)$. Carer ratings of target behaviour on the Visual Analogue Scale (VAS) did not change (mean 6.4 (sd 1.4) vs 6.5 (sd 1.4), $p=0.76$ ). The subgroup who reduced antipsychotic dose but did not progress to full discontinuation also showed a statistically significant decline in mean $A B C$ score from baseline to follow-up (62 (sd 27) vs 50 (sd 36), $p=0.03$ ), although with a simultaneous increase in severity of challenging behaviour measured by the VAS (6.4 (sd 1.4) vs 5.8 (sd 1.6), $p=0.03$ ). Thus, the findings of the VAS potentially contradict the improvement in behaviour measured by the $A B C$. The authors suggest bias in the VAS scores introduced by caregivers who have the expectation of deterioration following antipsychotic reduction as a possible explanation. A further paradox in this study is that those in the group who reduced but did not discontinue antipsychotics were said not to have progressed to discontinuation "if there was a significant behavioural worsening according to the clinician's judgement", suggesting that this group is, in fact, defined by subjective deterioration in behaviour.

May et al. monitored challenging behaviour of a group of adult men with severe-profound ID over the course of antipsychotic withdrawal to discontinuation using frequency counts. ${ }^{48}$ Using a very slow regime of antipsychotic taper and following individuals for at least 3 years, distinct groups became apparent. Five individuals (22\%) showed progressive improvement in behaviour coinciding with antipsychotic reduction, 9 (39\%) demonstrated transient worsening, and 9 (39\%) experienced persistent behavioural worsening requiring prescription of either antipsychotics or other psychotropics. Those who experienced a progressive improvement on antipsychotic withdrawal tended to demonstrate greater baseline frequency of challenging behaviour. However, the study was under-powered for observed differences to reach statistical significance.

Swanson measured total $A B C$ score at baseline, three subsequent time-points during antipsychotic dose reduction, and after discontinuation. ${ }^{39}$ Total $A B C$ score increased during withdrawal before falling.

Branford describes the outcome of antipsychotic reduction attempts in 123 patients. ${ }^{44}$ One quarter achieved discontinuation without any deterioration in behaviour, $42 \%$ experienced deterioration in behaviour necessitating re-prescribing or attenuation of dose reduction. Behaviour change of the remaining individuals (33\%) was not reported.

Janowsky et al. report outcome at three months following antipsychotic reduction attempts in a group of 138 participants. ${ }^{45}$ Whilst $60 \%$ tolerated discontinuation, the remainder had a "significant increase in maladaptive target symptoms" which required antipsychotic represcribing or dose increase. The same authors report a follow-up study of 49 of those who failed attempts to discontinue antipsychotic medication; $96 \%$ experienced behavioural relapse in future attempts to discontinue medication. ${ }^{46}$ 
Effect of reduction or discontinuation of antipsychotics on physical health

Ten studies reported physical health outcomes resulting from antipsychotic reduction or discontinuation. ${ }^{32,35,37-39,47,49-52}$ Below we report physical health outcome grouped by theme.

\section{Movement effects}

Several studies that reported movement effects of antipsychotic reduction or discontinuation used the Dyskinesia Identification System: Condensed User Scale (DISCUS), a scale specifically developed to measure abnormal movements in individuals with ID. ${ }^{53}$ Fifteen items relating to movement of different body regions are rated from 0 (not present) to 4 (severe). Categorical definitions for clinically-relevant dyskinesia have been developed based on the total DISCUS score. ${ }^{54,55}$

Wigal et al compared change in DISCUS score at baseline and 10-month follow-up between four groups defined by increase in antipsychotic dose, no change, antipsychotic dose reduction by $<25 \%$, and antipsychotic dose reduction $\geq 25 \%$ (but not matched by any other characteristic). ${ }^{37}$ Follow-up mean DISCUS score increased in all groups apart from the dose increase group, with the degree of dose reduction being positively correlated with increase in DISCUS score $(r=0.506, p<0.001)$. Employing a categorical definition of dyskinesia (at least a 'mild' rating of abnormal movements in at least two body regions, or at least a 'moderate' rating of abnormal movements in one body region), ${ }^{55}$ the authors found the rate of dyskinesia increased from $30 \%$ at baseline to $60 \%$ at follow-up in the group who reduced medication by $>25 \%$, but remained stable in the groups who reduced medication by a lesser percentage or who underwent no dose change.

A later study by the same group reports a small controlled study of 30 individuals with nested controls defined by antipsychotic dose changes. ${ }^{38} 63 \%$ of those who discontinued antipsychotic medication developed tardive dyskinesia compared with $29 \%$ of those undergoing dose reduction and none of the controls or those who underwent antipsychotic dose increase or no change.

A third study by this group reports results of antipsychotic discontinuation in 40 people and compare DISCUS scores with a control group at several time-points. ${ }^{39}$ The participants are further subdivided by anticonvulsant use, producing 4 groups in total. Mean DISCUS score increased after antipsychotic discontinuation in the group taking antipsychotics alone but not in the group who received concomitant treatment with anticonvulsant medication, raising the possibility of a mitigating effect of anticonvulsants in reducing discontinuation reactions.

Ahmed et al found total DISCUS score was significantly increased at 6 month follow-up in the group who discontinued antipsychotics or underwent $\geq 50 \%$ dose reduction compared with controls $(p<0 \cdot 01) .{ }^{32}$ The DISCUS score in the intervention group fell between month 5 and 6 , possibly indicating the start of a return to baseline.

The concept of a 'transient withdrawal dyskinesia' is developed in three studies by Newell et al who prospectively monitored individuals undergoing planned antipsychotic dose reduction 
to discontinuation. ${ }^{49-51}$ The authors investigated change in movement disorder over time with DISCUS rating and by using proxies for movement abnormalities. The first investigated lip movements associated with dyskinesia and demonstrated changes in quality and quantity of resting lip motion over the course of antipsychotic reduction and discontinuation that tended to revert to the pre-reduction state at follow up 6-24 months after discontinuation. ${ }^{49}$ In the second study, the authors again report change in DISCUS score; mean total DISCUS score increased from 3.4 at baseline to 10.7 at peak withdrawal $(p<0.001)$, before falling to approximate baseline values at follow-up (mean follow-up DISCUS 3.5, $p=\mathrm{NS}$ ). Rates of tardive dyskinesia showed a similar pattern, increasing from $31 \%$ at baseline to $85 \%$ at peak withdrawal, and then dropping to $38 \%$ at follow-up. ${ }^{51}$ Data presented in the third of these studies reports postural stability as a measure of movement disorder. ${ }^{50}$ Indices of postural stability and body motion changed significantly over the course of antipsychotic withdrawal and returned to baseline levels by follow-up. Mean total DISCUS increased from 3.5 at baseline (range 0-11), to 11.1 at peak withdrawal (range 3-22), and 3.8 at follow-up (range 011) ( $p<0.01$ for difference over time). This study extends the analysis by reporting a positive association between higher baseline levels of movement symptoms and the degree of withdrawal-associated dyskinesia, thereby giving some indication of people who might be more prone to develop problematic dyskinesia on medication reduction.

deKuijper et al report movement side-effects as a composite of clinician-assessed Parkinsonism, akathisia, and extra-pyramidal side-effect ratings. ${ }^{47}$ Reporting of this outcome is incomplete but there was little change in average movement side-effect score between baseline and at the point of antipsychotic discontinuation in those who completed withdrawal (baseline score $2 \cdot 8$, follow-up $3 \cdot 0, p$ not given).

\section{Autonomic function}

Despite disturbance of autonomic function being a known side-effect of antipsychotic drugs, only two studies reported the autonomic effects of their reduction or discontinuation. ${ }^{35,47}$ deKuijper ${ }^{47}$ used the Scale Outcomes Parkinson's disease-Autonomic symptoms (SCOPA-AUT) to assess autonomic adverse events at baseline and following reduction or discontinuation of antipsychotics. ${ }^{56}$ Both the group achieving discontinuation and the group who underwent dose reduction short of complete discontinuation showed significantly decreased SCOPA-AUT scores at 12 week follow-up (in the discontinuation group mean SCOPA-AUT changed from 6.0 to $3.6, p<0.01$; in the dose reduction group mean SCOPA-AUT changed from 6.0 to 4.9 , $p<0.01$ ) indicating a lower burden of autonomic symptoms and a dose-response relationship.

In a case report, Orfan and Kolski describe the outcome of fluphenazine withdrawal in a 74 year old woman with ID who received the drug for behaviour control. ${ }^{35}$ The patient developed "severe and debilitating" rhinorrhoea following antipsychotic discontinuation.

Weight / metabolic parameters

Ahmed et al compared weight change between a group who discontinued or reduced antipsychotic dose by $\geq 50 \%$ and a control group who underwent no medication change. ${ }^{32}$ Those in the intervention group lost an average of $2.3 \mathrm{~kg}$ at 6 months, although this was not statistically different from weight change observed in controls (data not given, $p>0.05$ ). 
deKuijper reports change in weight, BMI, and several metabolic parameters in a subgroup of participants who achieved antipsychotic discontinuation and remained antipsychotic free at 12 weeks. ${ }^{52}$ Waist circumference, weight, and BMI were all significantly reduced at follow-up compared with baseline (waist circumference $93.2 \mathrm{~cm}$ vs $88.8 \mathrm{~cm}, p<0.001$; weight $68.7 \mathrm{~kg}$ vs $65.2 \mathrm{~kg}, p=0.02 ; \mathrm{BMI} 25 \mathrm{~kg} / \mathrm{m}^{2}$ vs $23.66 \mathrm{~kg} / \mathrm{m}^{2}, p=0.006$ ). Systolic, but not diastolic blood pressure also showed a significant fall (systolic $129 \mathrm{mmHg}$ vs $122 \mathrm{mmHg}, p=0 \cdot 02$; diastolic $80 \mathrm{mmgHg}$ vs $75 \mathrm{mmHg}, p=\mathrm{NS}$ ). Laboratory markers of the metabolic syndrome (plasma triglycerides, HDL, and fasting glucose) did not change significantly, although this might be a reflection of the relatively short duration of follow-up.

Effect of reduction or discontinuation of antipsychotics on mental health

No studies reported the effect of reduction or discontinuation of antipsychotics on the mental health of participants.

\section{Effect of reduction or discontinuation of antipsychotics on cognitive/adaptive functioning}

Four studies reported impact of reduction or discontinuation of antipsychotics on cognitive or adaptive function. In a small controlled study, Carpenter and colleagues report the effect on performance in a standardised computer-based cognitive test in which participants are required to match colours. ${ }^{36}$ All of those undergoing antipsychotic dose reduction or discontinuation demonstrated improved performance on the test compared with none of those with no medication change or not on an antipsychotic drug (number of attempts to reach 4 consecutive correct responses reduced by average of $29 \%$ in withdrawal group (range $13 \cdot 8-53.5 \%$ ) and by $0.4 \%$ in control group (range $0.3 \%-0.7 \%$ ); percentage of correct responses increased by average of $10 \%$ in withdrawal group (range $2.7 \%-19.7 \%$ ) but declined by $1.5 \%$ in controls (range $1.3 \%--4.9 \%$ ); statistical tests not performed).

Gedye reports the results of a small case series $(n=4) \cdot{ }^{34}$ All had demonstrated cognitive decline and been diagnosed clinically with dementia, at an average age of 42 years. Reduction and later discontinuation of antipsychotic medication resulted in substantial and sustained clinician-rated improvement in overall cognitive and adaptive function such that the diagnosis of dementia was no longer applicable.

Ahmed et al ${ }^{32}$ directly observed participant behaviour for a random 1.5 hour period three times a month during their 6 month study and collated the amount of time participants spent in each of several pre-defined activities, including a measure of engagement in the activity. Full results are not reported but the authors state that the group who discontinued antipsychotics or had at least $50 \%$ dose reduction spent significantly more time engaged in activity than controls $(p<0.05)$. Additional data obtained in the same study focus specifically on responsiveness to staff interaction. ${ }^{33}$ No difference in likelihood of response to staff interaction was found between the groups, probably as a high baseline response was recorded. 
As part of a separate search, we identified studies that report factors associated with success of attempts to reduce or discontinue antipsychotic reduction (table 3). Relatively good evidence shows that those who have previously failed attempts to reduce antipsychotic medication are poor candidates for further attempts to stop medication. ${ }^{46}$ Studies tend to be in agreement that those on a lower baseline antipsychotic dose are more likely to have successful withdrawal. ${ }^{47,48,57,58}$ Other predictors of successful withdrawal attempts are less clear and are sometimes conflicting between studies (e.g. gender). Those with a high level of psychopathology (whether psychotic or not) seem to be more likely to relapse when an antipsychotic is withdrawn; ${ }^{57,59}$ these may be people with co-morbid mental illness which deteriorates when an their medication is reduced. The use of concomitant psychotropics (including antiepileptic drugs) has been shown to be of benefit in facilitating antipsychotic withdrawal attempts, ${ }^{59}$ although this is not a consistent finding. ${ }^{48,57}$

\section{Discussion}

A significant proportion of individuals in whom a concerted effort was made to reduce antipsychotic drugs achieved discontinuation or dose reduction. This suggests that clinicians can reasonably attempt to reduce antipsychotics in patients who are prescribed them for challenging behavioural. However, it is also the case that many of those in whom attempts were made to reduce or discontinue antipsychotic medication could not tolerate reduction and required re-prescribing. Stevenson and colleagues, writing in the aftermath of the restrictions imposed on the use of the first-generation agent thioridazine in 2000, contested that wide-scale antipsychotic withdrawal in this group is likely to cause serious harm, including precipitating increases in behaviour problems and mental ill-health. ${ }^{60}$

Overall results from studies that report behavioural outcomes are inconclusive. Both deKuijper et $\mathrm{al}^{47}$ and Ahmed et al ${ }^{32}$ report no change, or even improvement in behaviour after antipsychotic discontinuation, although those whose behaviour deteriorated did not complete the withdrawal programme. Other studies report between $40 \%$ and $96 \%$ of those undergoing dose reduction experience significant behavioural deterioration which could persist for several years. ${ }^{44-46,48}$

None of the included studies investigated mechanisms underlying behavioural deterioration following antipsychotic reduction or discontinuation. Hypotheses related to a pathophysiological discontinuation syndrome include; onset of super-sensitivity psychosis; cholinergic and/or adrenergic rebound; and emergence of movement side-effects such as withdrawal dyskinesia or tardive akathisia. ${ }^{61}$ In all cases, the impact of symptoms may be greater in people with ID due to limitations in understanding and communicating distress verbally, which may then find expression as challenging behaviour. Slow taper of antipsychotic medication has been advocated in order to minimise the risk of these discontinuation effects ${ }^{62}$ although the only study that compared rates of antipsychotic taper did not find any advantage in stopping the medication over a period of longer than 14 weeks. ${ }^{47}$

One of the most consistent findings of the review is the transient increase in dyskinesia that accompanied antipsychotic reduction or discontinuation associated with the use of both first- 
and second-generation agents. ${ }^{63}$ Dyskinesia on antipsychotic reduction appears to be proportionate to the degree of dose reduction and may persist for several months. A return to baseline measures of dyskinesia was noted in studies employing longer follow-up periods, suggesting that it remits over time.

Weight loss and some improved markers of the metabolic syndrome were noted when antipsychotics were reduced or discontinued. ${ }^{32,52}$ This is an important consideration in adults with ID who are more likely to be obese than peers of average intelligence ${ }^{64}$, and less likely to eat a balanced diet or achieve minimum recommended physical activity targets. ${ }^{65}$

Antipsychotic medication may reduce cognitive ability in people with ID, either due to increased somnolence and sedation ${ }^{66,67}$ or their anti-cholinergic properties. Where change in cognition was investigated there was some evidence of improvement in those who reduced or discontinued antipsychotics. This warrants further attention given that reductions in cognitive capacity might negatively impact the success of psychosocial management of challenging behaviour and interfere with habilitation programmes.

\section{Limitations of existing research and directions for future research}

A major finding of the review is that current literature on the feasibility and outcome of antipsychotic withdrawal in people with ID is lacking in volume, quality and scope. Critical appraisal (table 1) revealed trials including small numbers of participants, selection bias and use of convenience samples, lack of control groups and of blinding, lack of standardised or validated outcome measures, and incomplete outcome reporting or statistical testing. The studies were often naturalistic and the intervention to reduce or discontinue antipsychotics was not well described. The length of follow-up was often short and may have been insufficient to capture some important outcomes. Studies may have included other simultaneous interventions that were not reported and could have confounded the results. No studies addressed the effect of reduction or discontinuation of antipsychotics on participant's mental health, despite withdrawal of antipsychotics having been associated with new-onset psychotic symptoms even in those without previous psychosis. ${ }^{68}$ These significant methodological shortcomings limit the internal and external validity of the results and the strength of conclusions we are able to draw.

[Panel 2 near here]

\section{Systematic review - strengths and limitations}

This is the first study of which we are aware that has attempted to consolidate current knowledge on this topic. Our search strategy was comprehensive, conducted according to a pre-defined protocol, and undertaken in several databases. We included all types of outcome measure in order to present a broad analysis.

There are some limitations of our review. We chose to exclude studies published before 1990 as we felt that the relatively rapid changes in understanding and care of people with ID make it difficult to generalise results of earlier studies to current practice. Despite this date limit, a 
number of studies that we included were conducted in large residential institutions for people with ID. Most studies include a high proportion of people with severe-profound ID who constitute only a minority of the total intellectually disabled population.

Most people in included studies were taking a first-generation antipsychotic drug. This might limit the relevance of the review findings although there is evidence that a significant proportion of people taking antipsychotics still receive first-generation agents. ${ }^{69}$

\section{Conclusions and implications for practice}

Antipsychotics are likely to have a role in the multi-modal management of certain cases of challenging behaviour in people with ID but clinicians must respond to the prevailing attitude that these drugs have too often been used indiscriminately and for too long. Evidence-based practice guidelines and quality indicators have been developed to improve antipsychotic prescribing for challenging behaviour. ${ }^{11,70-72}$ These focus on the holistic assessment and management of challenging behaviour and the initiation of antipsychotic medication, rather than addressing antipsychotic discontinuation. There remains relatively little information to guide practice in reducing or discontinuing antipsychotics in the cohort who are already taking these drugs.

In terms of predictors of successful or unsuccessful reduction or discontinuation of antipsychotics, setting and carer characteristics (as well as some individual traits) were shown to be important consistent with previous research. Working conditions, staff experience, and attributions about challenging behaviour can influence how behaviour is reported and how it is managed. ${ }^{73-75}$ Where psychotropic medication is used, carers often report inadequate training and a desire for more information. ${ }^{76,77}$ These deficiencies in knowledge and skills can act as a barrier to appropriate monitoring of antipsychotics in this group, particularly as clinicians are often heavily reliant on third-party reports of drug effects. ${ }^{78}$ Living environment is similarly important in influencing prescribing; a four-fold difference in rates of antipsychotic prescription for behaviour has been demonstrated between those living in institutions and those residing in family homes, despite no underlying difference in the rates of behaviour disorder. ${ }^{79}$ Clearly, any attempt to transform antipsychotic prescribing to people with ID must recognise the wider elements that may directly influence drug use and which individual clinicians have little power to change. ${ }^{80}$

This review exposes a gap between the available evidence and the national policy drive to reduce antipsychotic prescribing to people with ID. We are not able to recommend a routine programme of antipsychotic discontinuation in people with ID who use the drugs for challenging behaviour and advocate a measured response according to published guidelines. ${ }^{72}$ As contextual factors are important, commissioning of appropriate provider services and support for carers is paramount. No amount of goodwill will be sufficient to drive a change in the current status quo unless a systems approach to prescribing is considered. ${ }^{80}$ 


\section{Contributors}

$\mathrm{RS}$ and $\mathrm{AH}$ designed the protocol. RS completed the literature search and data synthesis. RS and AH interpreted the results. RS and $\mathrm{AH}$ wrote the manuscript.

\section{Declaration of interests}

RS declares no competing interests.

AH was a member of the NICE Guideline 'Challenging behaviour and learning disabilities: prevention and interventions for people with learning disabilities whose behaviour challenges' (NG11). 


\section{References}

1. American Psychiatric Association. Diagnostic and statistical manual of mental disorders. Arlington, VA: American Psychiatric Publishing; 2013.

2. Sheehan R, Hassiotis A, Walters K, Osborn D, Strydom A, Horsfall L. Mental illness, challenging behaviour, and psychotropic drug prescribing in people with intellectual disability: UK population based cohort study. BMJ 2015; 351: h4326.

3. Holden B, Gitlesen JP. Psychotropic medication in adults with mental retardation: prevalence, and prescription practices. Res Dev Disabil 2004; 25: 509-21.

4. Emerson E. Challenging Behaviour: Analysis and Intervention in People with Severe Intellectual Disabilities. 2nd ed. Cambridge: Cambridge University Press; 2001.

5. Emerson E, Kiernan C, Alborz A, et al. The prevalence of challenging behaviors: a total population study. Res Dev Disabil 2001; 22: 77-93.

6. Holden B, Gitlesen JP. A total population study of challenging behaviour in the county of Hedmark, Norway: Prevalence, and risk markers. Res Dev Disabil 2006; 27: 456-65.

7. Cooper S-A, Smiley E, Morrison J, Williamson A, Allan L. Mental ill-health in adults with intellectual disabilities: prevalence and associated factors. Br J Psychiatry 2007; 190: 27-35.

8. Royal College of Psychiatrists, British Psychological Society, Royal College of Speech and Language Therapists. Challenging behaviour: a unified approach. Royal College of Psychiatrists. London: 2007.

9. Deb S, Sohanpal S, Soni R, Lentre L, Unwin G. The effectiveness of antipsychotic medication in the management of behaviour problems in adults with intellectual disabilities. J Intellect Disabil Res 2007; 51: 766-77.

10. Matson JL, Neal D. Psychotropic medication use for challenging behaviors in persons with intellectual disabilities: An overview. Res Dev Disabil 2009; 30: 572-86.

11. National Institute for Health and Care Excellence. Challenging Behaviour and Learning Disabilities: Prevention and Interventions for People with Learning Disabilities Whose Behaviour Challenges (NICE Guideline NG11). NICE. 2015.

12. Matson JL, Bamburg JW, Mayville EA, et al. Psychopharmacology and mental retardation: a 10 year review (1990-1999). Res Dev Disabil 2000; 21: 263-96.

13. Tsiouris J. Pharmacotherapy for aggressive behaviours in persons with intellectual disabilities: treatment or mistreatment? J Intellect Disabil Res 2010; 54: 1-16.

14. Tyrer P, Cooper S-A, Hassiotis A. Drug treatments in people with intellectual disability and challenging behaviour. BMJ 2014; 349: g4323.

15. Glover G, Bernard S, Branford D, Holland A, Strydom A. Use of medication for challenging behaviour in people with intellectual disability. Br J Psychiatry 2014; 205: 6-7.

16. Department of Health. Transforming care: A national response to Winterbourne View Hospital: Department of Health Review Final Report. Department of Health. London: 2012.

17. Public Health England. Prescribing of psychotropic drugs to people with learning disabilities and/or autism by general practitioners in England. Public Health England. London: 2015.

18. Marshall T. Audit of the use of psychotropic medication for challenging behaviour in a community learning disability service. The Psychiatrist 2004; 28: 447-50.

19. Deb S, Unwin G, Deb T. Characteristics and the trajectory of psychotropic medication use in general and antipsychotics in particular among adults with an intellectual disability who exhibit aggressive behaviour. J Intellect Disabil Res 2015; 59: 11-25.

20. de Leon J, Greenlee B, Barber J, Sabaawi M, Singh NN. Practical guidelines for the use of new generation antipsychotic drugs (except clozapine) in adult individuals with intellectual disabilities. Res Dev Disabil 2009; 30: 613-69.

21. Campbell N, Boustani M, Limbil T, et al. The cognitive impact of anticholinergics: a clinical review. Clinical Interventions in Aging 2009; 4: 225-33. 
22. Fox C, Smith T, Maidment I, et al. Effect of medications with anti-cholinergic properties on cognitive function, delirium, physical function and mortality: a systematic review. Age Ageing 2014; 43: 604-15.

23. Arnold LE. Clinical pharmacological issues in treating psychiatric disorders of patients with mental retardation. Ann Clin Psychiatry 1993; 5: 189-97.

24. Wyatt RJ. Research in schizophrenia and the discontinuation of antipsychotic medications. Schizophr Bull 1997; 23: 3-9.

25. Jeste DV, Palmer BW, Harris MJ. Neuroleptic discontinuation in clinical and research settings: scientific issues and ethical dilemmas. Biol Psychiatry 1999; 46: 1050-9.

26. Pan YJ, Wu CS, Gau SSF, Chan HY, Banerjee S. Antipsychotic Discontinuation in Patients with Dementia: A Systematic Review and Meta-Analysis of Published Randomized Controlled Studies. Dement Geriatr Cogn Disord 2014; 37: 125-40.

27. Declercq T, Petrovic M, Azermai M, et al. Withdrawal versus continuation of chronic antipsychotic drugs for behavioural and psychological symptoms in older people with dementia. Cochrane Database Syst Rev 2013.

28. Troost PW, Lahuis BE, Steenhuis M-P, et al. Long-term effects of risperidone in children with autism spectrum disorders: a placebo discontinuation study. J Am Acad Child Adolesc Psychiatry 2005; 44: 1137-44.

29. Reyes M, Buitelaar J, Toren P, Augustyns I, Eerdekens M. A randomized, double-blind, placebo-controlled study of risperidone maintenance treatment in children and adolescents with disruptive behavior disorders. AJ Psychiatry 2006; 163: 402-10.

30. Research Units on Pediatric Psychopharmacology Autism Network. Risperidone treatment of autistic disorder: longer-term benefits and blinded discontinuation after 6 months. AJ Psychiatry 2005.

31. Howick J, Chalmers, I., Glasziou, P., Greenhalgh, T., Heneghan, C., Liberati, A., Moschetti, I., Phillips, B., Thornton, H. Explanation of the 2011 Oxford Centre for Evidence-Based Medicine (OCEBM) Levels of Evidence (Background Document). Oxford Centre for Evidence-Based Medicine. 32. Ahmed Z, Fraser W, Kerr MP, et al. Reducing antipsychotic medication in people with a learning disability. Br J Psychiatry 2000; 176: 42-6.

33. Smith C, Felce D, Ahmed Z, et al. Sedation effects on responsiveness: Evaluating the reduction of antipsychotic medication in people with intellectual disability using a conditional probability approach. J Intellect Disabil Res 2002; 46: 464-71.

34. Gedye A. Neuroleptic-induced dementia documented in four adults with mental retardation.[Erratum appears in Ment Retard 1999 Apr;37(2):138]. Ment Retard 1998; 36: 182-6. 35. Orfan NA, Kolski GB. Rhinorrhea related to antipsychotic drug therapy. J Allergy Clin Immunol 1993; 91: 681-2.

36. Carpenter M, Cowart CA, McCallum R, Bell SM. Effects of antipsychotic medication on discrimination learning for institutionalized adults who have mental retardation. Behavioral Residential Treatment 1990; 5: 105-20.

37. Wigal T, Christian DL, Wigal SB, et al. Classification of types of tardive dyskinesia in a developmentally disabled population at a public residential facility. J Dev Phys Disabil 1993; 5: 55-69.

38. Wigal T, Swanson JM, Christian DL, et al. Admissions to a public residential facility for individuals with developmental disabilities: Change in neuroleptic drug use and tardive dykinesia. $J$ Dev Phys Disabil 1994; 6: 115-24.

39. Swanson JM, Christian DL, Wigal T, et al. Tardive dyskinesia in a developmentally disabled population: Manifestation during the initial stage of a minimal effective dose program. Exp Clin Psychopharmacol 1996; 4: 218-23.

40. Hancock RD, Weber SL, Kaza R, Her KS. Changes in psychotropic drug use in long-term residents of an ICF/MR facility. Am J Ment Retard 1991; 96: 137-41.

41. Lepler S, Hodas A, Cotter-Mack A. Implementation of an interdisciplinary psychotropic drug review process for community-based facilities. Ment Retard 1993; 31: 307. 
42. Spreat S, Serafin C, Behar D, Leiman S. Tranquilizer reduction trials in a residential program for persons with mental retardation. Hosp Community Psychiatry 1993; 44: 1100-2.

43. Jauernig R, Hudson A. Evaluation of an Interdisciplinary Review Committee managing the use of psychotropic medication with people with intellectual disabilities. Australia and New Zealand Journal of Developmental Disabilities 1995; 20: 51-61.

44. Branford D. A review of antipsychotic drugs prescribed for people with learning disabilities who live in Leicestershire. J Intellect Disabil Res 1996; 40: 358-68.

45. Janowsky DS, Barnhill L, Khalid AS, Davis JM. Relapse of Aggressive and Disruptive Behavior in Mentally Retarded Adults Following Antipsychotic Drug Withdrawal Predicts Psychotropic Drug Use a Decade Later. J Clin Psychiatry 2006; 67: 1272-7.

46. Janowsky DS, Barnhill LJ, Khalid AS, Davis JM. Antipsychotic withdrawal-induced relapse predicts future relapses in institutionalized adults with severe intellectual disability. J Clin Psychopharmacol 2008; 28: 401-5.

47. de Kuijper G, Evenhuis H, Minderaa R, Hoekstra P. Effects of controlled discontinuation of long-term used antipsychotics for behavioural symptoms in individuals with intellectual disability. $J$ Intellect Disabil Res 2014; 58: 71-83.

48. May P, London EB, Zimmerman T, Thompson R, Mento T, Spreat S. A study of the clinical outcome of patients with profound mental retardation gradually withdrawn from chronic neuroleptic medication. Ann Clin Psychiatry 1995; 7: 155-60.

49. Newell KM, Bodfish JW, Mahorney SL, Sprague RL. Dynamics of lip dyskinesia associated with neuroleptic withdrawal. Am J Ment Retard 2000; 105: 260-8.

50. Newell KM, Ko YG, Sprague RL, Mahorney SL, Bodfish JW. Onset of dyskinesia and changes in postural task performance during the course of neuroleptic withdrawal. Am J Ment Retard 2002; 107: $270-7$.

51. Newell KM, Wszola B, Sprague RL, Mahorney SL, Bodfish JW. The changing effector pattern of tardive dyskinesia during the course of neuroleptic withdrawal. Exp Clin Psychopharmacol 2001; 9: 262-8.

52. de Kuijper G, Mulder H, Evenhuis H, Visser F, Hoekstra PJ. Effects of controlled discontinuation of long-term used antipsychotics on weight and metabolic parameters in individuals with intellectual disability. J Clin Psychopharmacol 2013; 33: 520-4.

53. Sprague RL, Kalachnik JE, Slaw KM. Psychometric properties of the dyskinesia identification system: Condensed user scale (DISCUS). Ment Retard 1989; 27: 141.

54. Kalachnik JE, Sprague RL. The Dyskinesia Identification System Condensed User Scale (DISCUS): reliability, validity, and a total score cut-off for mentally ill and mentally retarded populations. J Clin Psychol 1993; 49: 177-89.

55. Schooler NR, Kane JM. Research diagnoses for tardive dyskinesia. Arch Gen Psychiatry 1982; 39: 486-7.

56. Visser M, Marinus J, Stiggelbout AM, Van Hilten JJ. Assessment of autonomic dysfunction in Parkinson's disease: The SCOPA-AUT. Mov Disord 2004; 19: 1306-12.

57. Branford D. Factors associated with the successful or unsuccessful withdrawal of antipsychotic drug therapy prescribed for people with learning disabilities. J Intellect Disabil Res 1996; 40: 322-9.

58. Matthews T, Weston SN. Experience of thioridazine use before and after the Committee on Safety of Medicines warning. The Psychiatrist 2003; 27: 87-9.

59. Luchins DJ, Dojka D, Hanrahan P. Factors associated with reduction in antipsychotic medication dosage in adults with mental retardation. Am J Ment Retard 1993; 98: 165-72.

60. Stevenson C, Rajan L, Reid G, Melville C, McGilp R, Cooper S-A. Withdrawal of antipsychotic drugs from adults with intellectual disabilities. Ir J Psychol Med 2004; 21: 85-90.

61. Salomon C, Hamilton B. Antipsychotic discontinuation syndromes: A narrative review of the evidence and its integration into Australian mental health nursing textbooks. Int J Ment Health Nurs 2014; 23: 69-78. 
62. Verghese C, DeLeon J, Nair C, Simpson GM. Clozapine withdrawal effects and receptor profiles of typical and atypical neuroleptics. Biol Psychiatry 1996; 39: 135-8.

63. Urbano M, Spiegel D, Rai A. Atypical antipsychotic withdrawal dyskinesia in 4 patients with mood disorders. J Clin Psychopharmacol 2007; 27: 705-7.

64. Samele C, Seymour L, Morris B. A formal investigation into health inequalities experienced by people with learning difficulties and people with mental health problems-Area Studies Report. Disability Rights Commission. London: 2006.

65. Robertson J, Emerson E, Gregory N, et al. Lifestyle related risk factors for poor health in residential settings for people with intellectual disabilities. Res Dev Disabil 2000; 21: 469-86.

66. Aman M, Singh, N. Pharmacological intervention. In: Matson JL, Mulick, J., ed. Handbook of Mental Retardation. New York: Pergamon; 1991.

67. Wysocki T, Fuqua RW, Davis VJ, Breuning SE. Effects of thioridazine (Mellaril) on titrating delayed matching-to-sample performance of mentally retarded adults. Am J Ment Defic 1981; 85: 539-47.

68. Moncrieff J. Does antipsychotic withdrawal provoke psychosis? Review of the literature on rapid onset psychosis (supersensitivity psychosis) and withdrawal-related relapse. Acta Psychiatr Scand 2006; 114: 3-13.

69. Marston L, Nazareth I, Petersen I, Walters K, Osborn DP. Prescribing of antipsychotics in UK primary care: a cohort study. BMJ Open 2014; 4: e006135.

70. Deb S, Kwok H, Bertelli M, et al. International guide to prescribing psychotropic medication for the management of problem behaviours in adults with intellectual disabilities. World Psychiatry 2009; 8: 181-6.

71. Flood B, Henman MC. Building quality indicators for medication use in people aging with intellectual disabilities and behaviour disorders. Int J Dev Disabil 2015.

72. Royal College of Psychiatrists. Psychotropic drug prescribing for people with intellectual disability, mental health problems and/or behaviours that challenge: practice guidelines. Royal College of Psychiatrists. London: 2016.

73. Bromley J, Emerson E. Beliefs and emotional reactions of care staff working with people with challenging behaviour. J Intellect Disabil Res 1995; 39: 341-52.

74. Dagnan D, Cairns M. Staff judgements of responsibility for the challenging behaviour of adults with intellectual disabilities. J Intellect Disabil Res 2005; 49: 95-101.

75. Lambrechts $G$, Maes $B$. Analysis of staff reports on the frequency of challenging behaviour in people with severe or profound intellectual disabilities. Res Dev Disabil 2009; 30: 863-72.

76. Singh N, Ellis CR, Donatelli LS, et al. Professionals perceptions of psychotropic medication in residential facilities for individuals with mental retardation. J Intellect Disabil Res 1996; 40: 1-7.

77. Donley M, Chan J, Webber L. Disability support workers' knowledge and education needs about psychotropic medication. Br J Learn Disabil 2012; 40: 286-91.

78. Christian L, Snycerski S, Singh N, Poling A. Direct service staff and their perceptions of psychotropic medication in non-institutional settings for people with intellectual disability. J Intellect Disabil Res 1999; 43: 88-93.

79. Clarke DJ, Kelley S, Thinn K, Corbett JA. Psychotropic drugs and mental retardation: 1. Disabilities and the prescription of drugs for behaviour and for epilepsy in three residential settings. $J$ Intellect Disabil Res 1990; 34: 385-95.

80. Bamidele $\mathrm{K}$, Hall I. The place of medication for challenging behaviour: a whole system perspective. Advances in Mental Health and Intellectual Disabilities 2013; 7: 325-32.

81. Findholt NE, Emmett CG. Impact of interdisciplinary team review on psychotropic drug use with persons who have mental retardation. Ment Retard 1990; 28: 41.

82. Bisconer SW, Zhang X, Sine LF. Impact of a psychotropic medication and physical restraint review process on adults with mental retardation, psychiatric diagnoses, and challenging behaviors. $J$ Dev Phys Disabil 1995; 7: 123-35. 
83. Howerton K, Fernandez G, Touchette P, et al. Psychotropic medications in community based individuals with developmental disabilities: observations of an interdisciplinary team. Mental Health Aspects of Developmental Disabilities 2002; 5: 78-86.

84. Ruggerini C, Guaraldi GP, Russo A, Neviani V, Castagnini A. Integration of a psychiatric service in a long-term charitable facility for people with intellectual disabilities: a 5-year medication survey. Res Dev Disabil 2004; 25: 431-41.

85. Lim WWC. Use of psychoactive medications in Hong Kong institutions for adults with severe to profound learning disabilities: a retrospective study (1988-2003) and economic analysis. Journal of Applied Research in Intellectual Disabilities 2007; 20: 529-38.

86. Wressell SE, Tyrer SP, Berney TP. Reduction in antipsychotic drug dosage in mentally handicapped patients. A hospital study. Br J Psychiatry 1990; 157: 101-6.

87. Etherington J, Sheppard L, Ballinger B, Fenton G. Psychotropic drugs in a hospital for intellectual disability: the story of 18 years. Mental Handicap Research 1995; 8: 184-93.

88. Gravestock S. Regional audit of depot neuroleptic usage in adults with learning disabilities. The Psychiatrist 1996; 20: 289-91.

89. Branford D. A follow-up study of prescribing for people with learning disabilities previously in National Health Service care in Leicestershire, England. J Intellect Disabil Res 1997; 41: 339-45.

90. Branford D, Hutchins D. Tardive akathisia in people with mental retardation. J Dev Phys Disabil 1996; 8: 117-32.

91. Pary RJ. Discontinuation of neuroleptics in community-dwelling individuals with mental retardation and mental illness. Am J Ment Retard 1995; 100: 207-12.

92. Sovner R. Thioridazine Withdrawal-Induced Behavioral Deteriration Treated With Clonidine: Two Case Reports. Ment Retard 1995; 33: 221.

93. Davies SJ, Cooke LB, Moore AG, Potokar J. Discontinuation of thioridazine in patients with learning disabilities: balancing cardiovascular toxicity with adverse consequences of changing drugs. BMJ 2002; 324: 1519.

94. Margetić B, Aukst-Margetić B. Neuroleptic malignant syndrome and clozapine withdrawal at the same time? Prog Neuropsychopharmacol Bol Psychiatry 2005; 29: 145-7.

95. Stonecipher A, Galang R, Black J. Psychotropic discontinuation symptoms: a case of withdrawal neuroleptic malignant syndrome. Gen Hosp Psychiatry 2006; 28: 541-3.

96. Janowsky DS, Barnhill LJ, Shetty M, Davis JM. Minimally effective doses of conventional antipsychotic medications used to treat aggression, self-injurious and destructive behaviors in mentally retarded adults. J Clin Psychopharmacol 2005; 25: 19-25.

97. Haessler F, Glaser T, Pap A, Beneke M, Diefenbacher A, Reis O. A double-blind placebocontrolled discontinuation study of zuclopenthixol for the treatment of aggressive disruptive behaviours in adults with mental retardation-secondary parameter analyses. Pharmacopsychiatry 2008; 41: 232-9.

98. Häßler F, Glaser T, Reis O. Effects of zuclopenthixol on aggressive disruptive behavior in adults with mental retardation--a 2-year follow-up on a withdrawal study. Pharmacopsychiatry 2011; 44: 339-43.

99. Rapp JT, Swanson G, Dornbusch K. Temporary Increases in Problem Behavior and Sleep Disruption Following Decreases in Medication A Descriptive Analysis of Conditional Rates. Behav Modif 2007; 31: 825-46.

100. Levitas AS, Turk J, Bramble D, Hurley AD. Antipsychotics for aggression unrelated to a psychiatric diagnosis. Mental Health Aspects of Developmental Disabilities 2008; 11: 65. 
Consider antipsychotic medication in the management of challenging behaviour only when:

- Psychological or other interventions alone are not effective

- Treatment for co-morbid physical or mental disorders has been given

- The risk to the person or others is high

Only offer antipsychotic medication in combination with psychological or other interventions

Antipsychotic medication should be prescribed and initially monitored by a psychiatrist who should:

- Document the rationale for the medication

- Prescribe the lowest dose necessary

- Review the effectiveness and any side-effects after 3-4 weeks

- Develop a strategy for stopping the medication

- Stop the medication if there is no indication of response at 6 weeks

Antipsychotic medication should continue to be prescribed past 6 weeks only when supported by:

- Proven continued benefit of the drug

- Full multidisciplinary review at 3 months and every 6 months thereafter

Panel 1 Summary of guidelines on the use of antipsychotic medication to manage challenging behaviour, adapted from NICE NG11 11 
1018 citations identified (Medline 192; EMBASE 472;

PsycINFO 239; Cochran 37; CINAHL Plus 78)

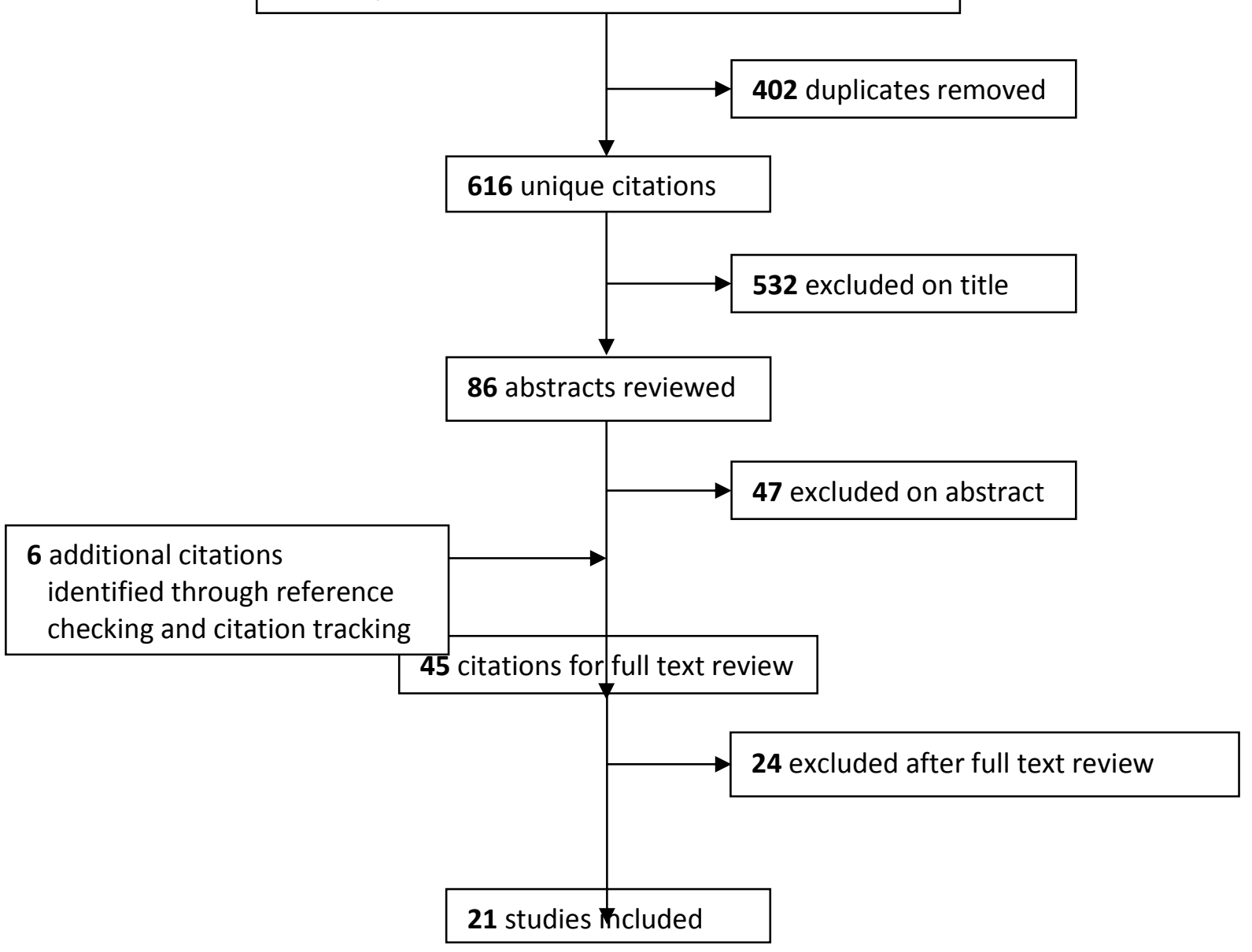

Figure 1 - study selection 


\begin{tabular}{|c|c|c|c|c|c|c|c|}
\hline $\begin{array}{l}\text { Study and level of } \\
\text { evidence (LE) }\end{array}$ & Participants & Setting & Intervention & Follow-up & Outcome & Results & $\begin{array}{l}\text { Bias and } \\
\text { limitations }\end{array}$ \\
\hline $\begin{array}{l}\text { Carpenter et al, } \\
1990 \\
\text { LE: } 3\end{array}$ & $\begin{array}{l}n=10 \\
90 \% \text { O } \\
\text { Mean age } 30 \text { yrs } \\
\text { ID: borderline } 10 \% \text {, } \\
\text { mild } 50 \% \text {, moderate } \\
\text { 10\%, severe } 30 \% \\
\text { Intervention group } \\
(n=7) \text { taking } \\
\text { antipsychotic for } \\
\text { challenging behaviour. } \\
\text { Control group ( } n=3 \text { ) } \\
\text { taking antipsychotic for } \\
\text { behaviour or no } \\
\text { antipsychotic } \\
\text { medication. One } \\
\text { control diagnosed with } \\
\text { schizophrenia. }\end{array}$ & $\begin{array}{l}\text { State institution } \\
\text { USA }\end{array}$ & $\begin{array}{l}\text { Reduction of } \\
\text { antipsychotic medication } \\
\text { by } 25-100 \% \text {, not } \\
\text { according to a pre- } \\
\text { defined schedule. No } \\
\text { medication changes in } \\
\text { controls. }\end{array}$ & $\begin{array}{l}\text { After medication } \\
\text { reduction or } \\
\text { discontinuation }\end{array}$ & $\begin{array}{l}\text { Performance on a } \\
\text { discrimination task } \\
\text { requiring matching of } \\
\text { colours presented } \\
\text { sequentially on a computer } \\
\text { screen; an initial colour is } \\
\text { presented, followed by a } \\
\text { delay, and then two colours } \\
\text { - the participant must } \\
\text { move a joystick in the } \\
\text { direction of the matching } \\
\text { colour for a correct } \\
\text { response. Performance } \\
\text { measured by a) trials } \\
\text { needed to achieve } 4 \\
\text { consecutive correct } \\
\text { responses and b) overall } \\
\text { percentage of correct } \\
\text { responses }\end{array}$ & $\begin{array}{l}\text { Intervention group improved in both } \\
\text { measures of performance (trials to } 4 \\
\text { consecutive correct responses - mean } \\
\text { improvement } 28.7 \% \text { reduction group vs. } \\
0.4 \% \text { for controls; percentage of correct } \\
\text { responses mean improvement } 10.2 \% \\
\text { reduction group vs. }-1.5 \% \text { control group) }\end{array}$ & $\begin{array}{l}(1) \\
(2) \\
(3) \\
(4) \\
(5) \\
(6) \\
(7) \\
(8)\end{array}$ \\
\hline $\begin{array}{l}\text { Hancock et al, } \\
1991 \\
\text { LE: } 4\end{array}$ & $\begin{array}{l}n=42 \\
42 \% \text { o } \\
\text { Mean age at entry } 28 \\
\text { yrs } \\
\text { ID: mild } 5 \%, \text { moderate } \\
5 \% \text {, severe } 7 \% \text {, } \\
\text { profound } 83 \%\end{array}$ & $\begin{array}{l}\text { State institution } \\
\text { USA }\end{array}$ & $\begin{array}{l}\text { Interdisciplinary team } \\
\text { programme to review } \\
\text { psychotropic medication } \\
\text { with a view to reduction } \\
\text { or discontinuation (not } \\
\text { according to a pre- } \\
\text { defined schedule) }\end{array}$ & $\begin{array}{l}5 \text { years } \\
10 \text { years }\end{array}$ & $\begin{array}{l}\text { Number discontinuing } \\
\text { antipsychotics } \\
\text { Number discontinuing } \\
\text { antipsychotics }\end{array}$ & $\begin{array}{l}\text { 10/42 (24\%) discontinued antipsychotics } \\
31 / 42(74 \%) \text { discontinued antipsychotics }\end{array}$ & $\begin{array}{c}(8) \\
(9) \\
(10)\end{array}$ \\
\hline & $\begin{array}{l}5 \% \text { psychiatric co- } \\
\text { morbidity (details not } \\
\text { given) } \\
\text { Antipsychotics: } \\
\text { Thioridazine }(n=36), \\
\text { chlorpromazine }(n=1) \text {, } \\
\text { haloperidol }(n=3) \text {, } \\
\text { mesoridazine }(n=3) \\
\text { (one participant on } 2 \\
\text { drugs) }\end{array}$ & & & & & & \\
\hline
\end{tabular}




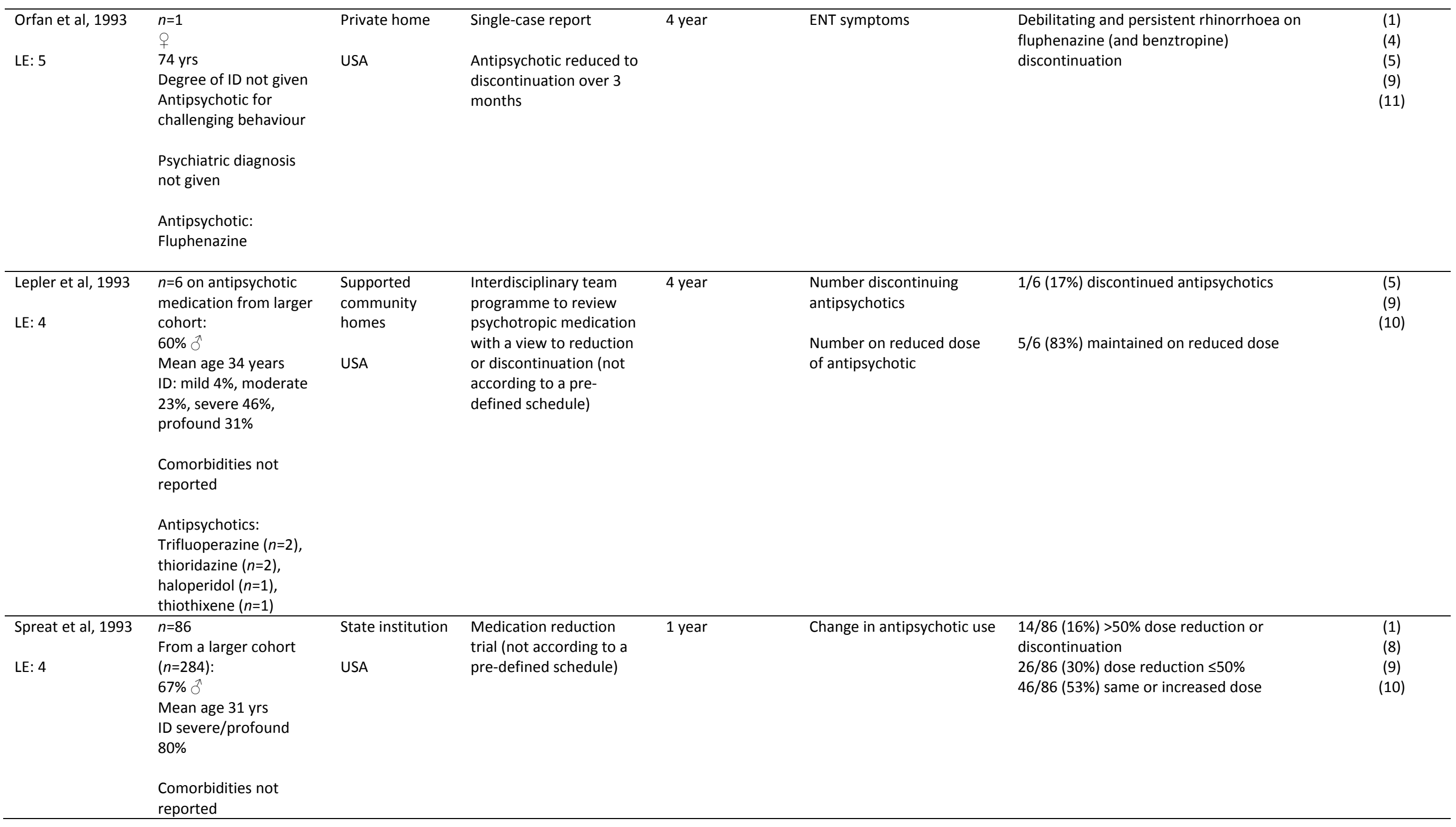


Antipsychotics (in

overall gretup):

Haloperidol $36 \%$,

mesoridazine $27 \%$,

thioridazine $15 \%$,

thioxanthene $6 \%$,

chlorpromazine $5 \%$,

trifluoperazine $4 \%$,

molindone $4 \%$,

fluphenazine $2 \%$,

chlorprothixene $2 \%$

\begin{tabular}{|c|c|c|c|c|c|c|c|}
\hline Wigal et al, 1993 & $n=56$ & State institution & Medication review and & 10 months & DISCUS score compared & No difference in DISCUS score between & (1) \\
\hline \multirow{15}{*}{ LE: 3} & Mean age 33 yrs & USA & programme (not & & undergoing at baseline (T1) & increased in NC, SD, and 25D groups - & (3) \\
\hline & ID: severe-profound & & according to a pre- & & and follow-up (T2) & greatest increase observed in 25D group. & (7) \\
\hline & $96 \%$ & & defined schedule) & & & DISCUS score at T2 decreased in the IN & (8) \\
\hline & & & & & & group. Significant correlation demonstrated & (9) \\
\hline & Comorbidities not & & Comparison of 4 & & & between degree of dose reduction and & (10) \\
\hline & reported & & $\begin{array}{l}\text { unmatched groups: } \\
\text { Increase in antipsychotic }\end{array}$ & & & DISCUS score $(r=0.506, p<0.001)$ & \\
\hline & Antipsychotics not & & dose $(\mathrm{IN}, n=5)$ & & Proportion with dyskinesia & Proportion with dyskinesia increased from & \\
\hline & reported by type & & No change in & & (Schooler \& Kane & $30 \%$ at $\mathrm{T} 1$ to $60 \%$ at $\mathrm{T} 2$ in the $25 \mathrm{D}$ group, did & \\
\hline & & & $\begin{array}{l}\text { antipsychotic dose (NC, } \\
n=14 \text { ) }\end{array}$ & & categorical definition ${ }^{55}$ ) & $\begin{array}{l}\text { not change in the SD or NC groups, and fell } \\
\text { from } 60 \% \text { to } 20 \% \text { in the IN group. }\end{array}$ & \\
\hline & & & Reduction in & & & & \\
\hline & & & antipsychotic dose of & & & & \\
\hline & & & $<25 \%(S D, n=21)$ & & & & \\
\hline & & & Reduction in & & & & \\
\hline & & & antipsychotic dose of & & & & \\
\hline & & & $\geq 25 \%(25 \mathrm{D}, n=16)$ & & & & \\
\hline \multirow[t]{2}{*}{ Wigal et al, 1994} & $n=245$ & State institution & Medication review and & 1 year & Number discontinuing & 141/245 (58\%) discontinued antipsychotic & (1) \\
\hline & From a larger cohort & & dose reduction & & antipsychotics & medication & (2) \\
\hline \multirow[t]{5}{*}{ LE: 4} & $(n=636):$ & USA & programme (not & & & & (3) \\
\hline & $67 \%$ क & & according to a pre- & & & & (7) \\
\hline & Mean age $24 \mathrm{yrs}$ & & defined schedule) & & & & (8) \\
\hline & ID: severe-profound & & & & & & (9) \\
\hline & $96 \%$ & & & & & & (10) \\
\hline
\end{tabular}




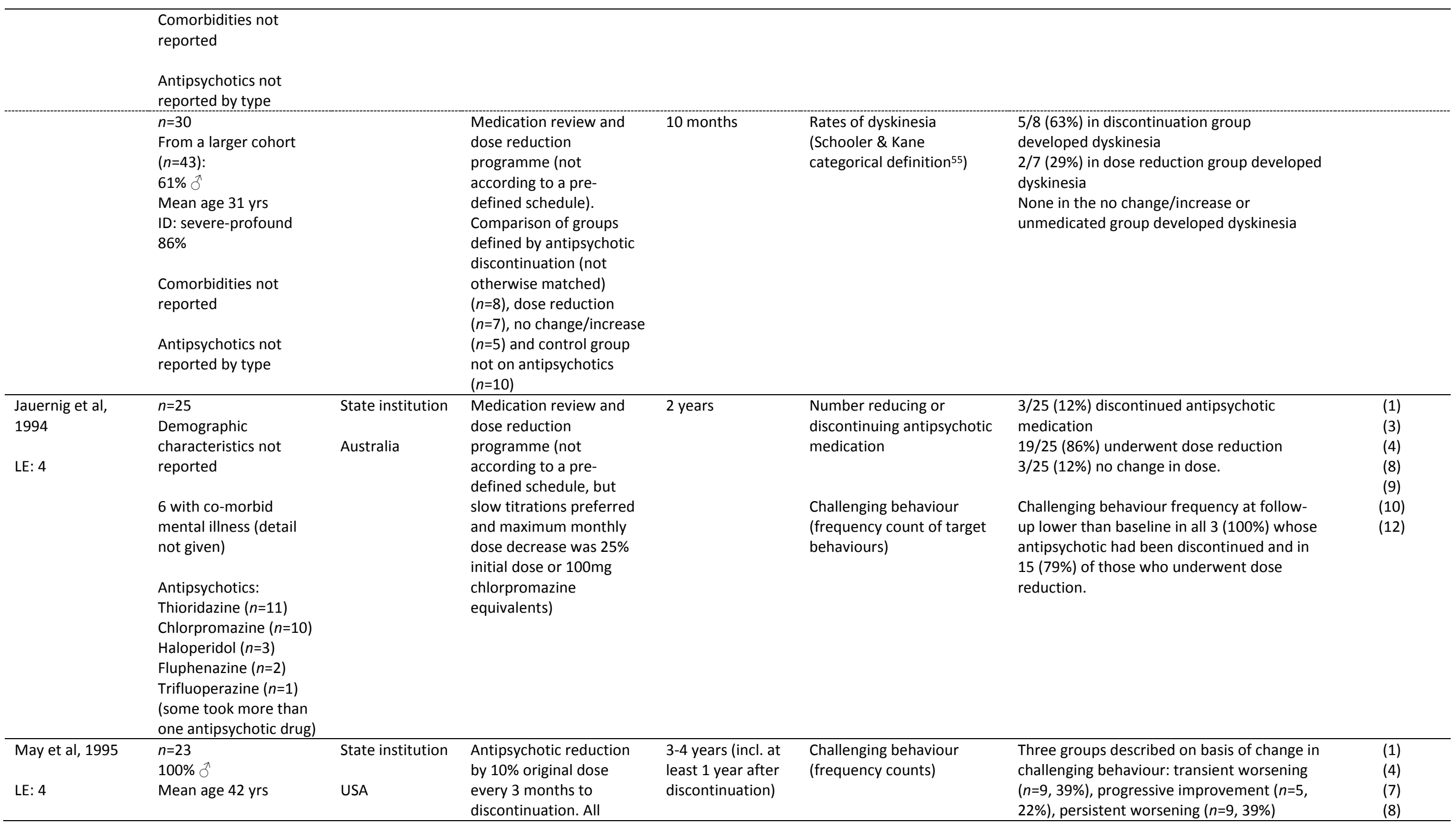




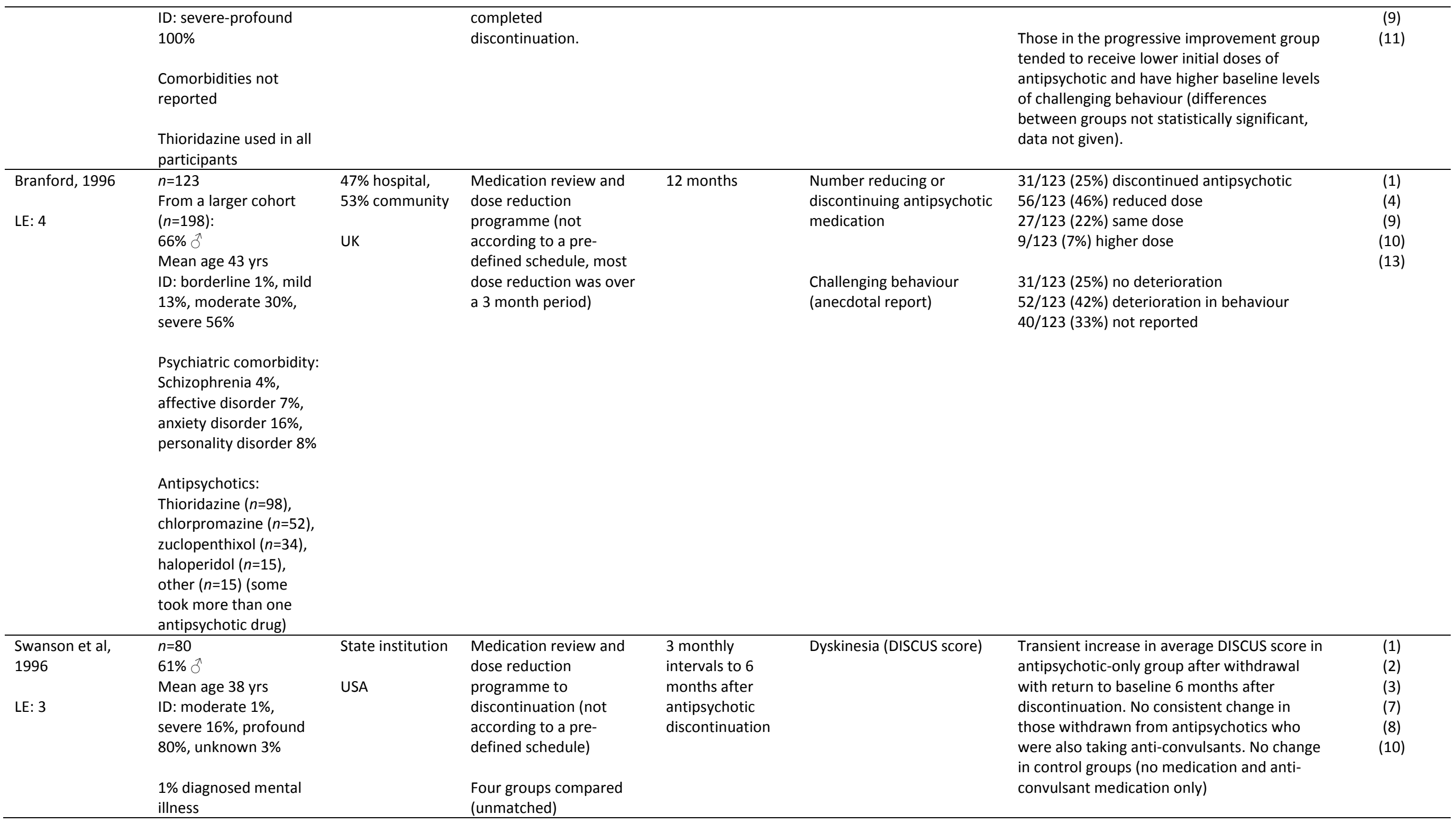




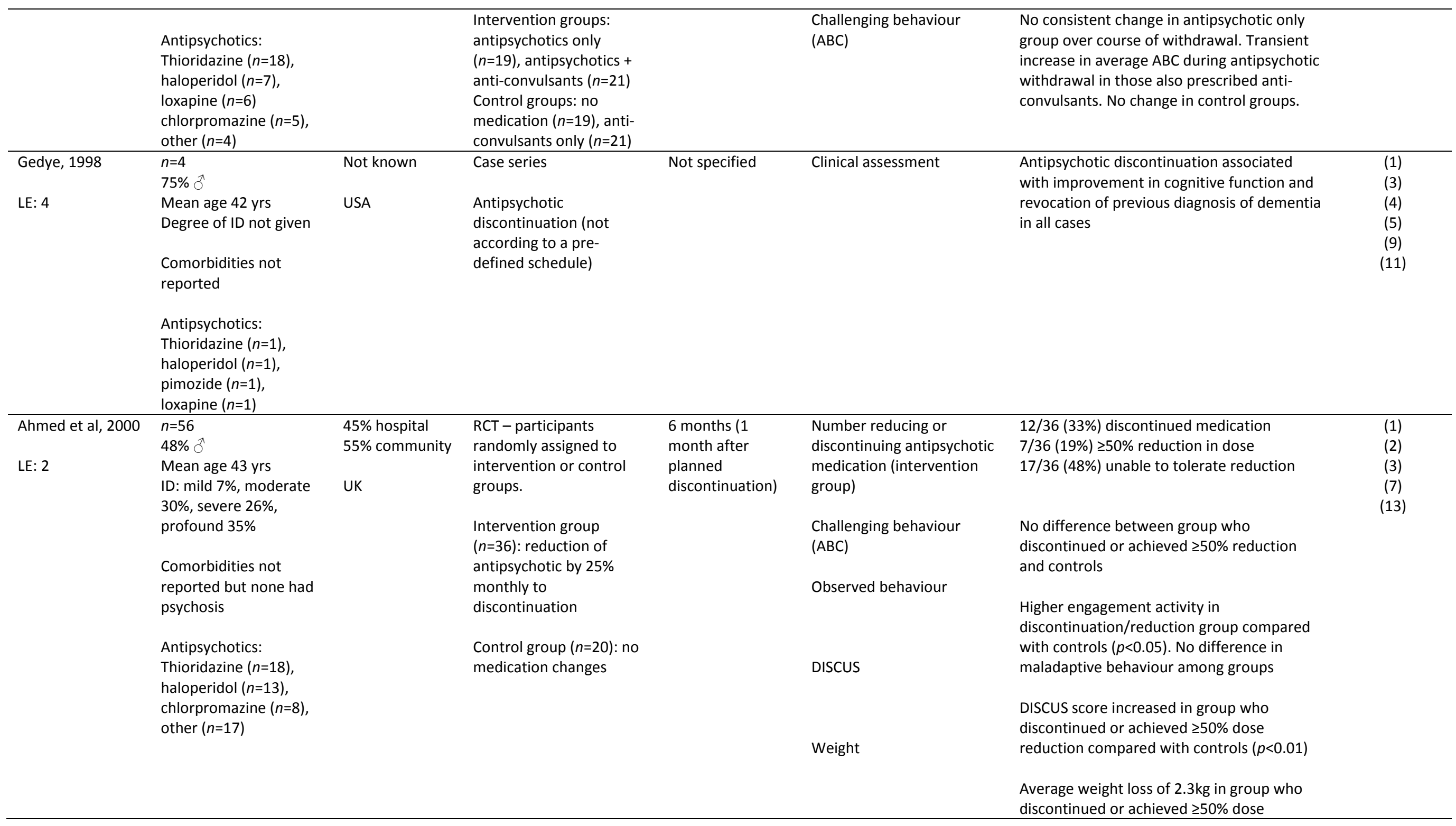




\begin{tabular}{|c|c|c|c|c|c|c|c|}
\hline & & & & & & $\begin{array}{l}\text { reduction but no statistically significant } \\
\text { difference from controls }\end{array}$ & \\
\hline \multirow[t]{2}{*}{ Newell et al, 2000} & $n=6$ & State institution & Antipsychotic dose & Post- & Video analysis of lip & Dyskinetic movements increased during & (1) \\
\hline & Mean age 37 vrs & & reduction by approx. $25 \%$ & discontinuation & movement (as proxy of TD) & antipsychotic withdrawal followed by a & (3) \\
\hline \multirow{10}{*}{ LE: 4} & ID. moderate $50 \%$ & USA & every 3 mths to & follow-up of & & reduction post-discontinuation, although not & (4) \\
\hline & severe $33 \%$, profound & & & & & to basellne levels & (7) \\
\hline & $17 \%$ & & & & DISCUS score & Results not given & (8) \\
\hline & & & & & & & (9) \\
\hline & No comorbidities & & & & & & (12) \\
\hline & & & & & & & (13) \\
\hline & Antipsychotics: & & & & & & \\
\hline & haloperidol ( $n=3$ ) & & & & & & \\
\hline & thioridazine $(n=2)$ & & & & & & \\
\hline & Mesoridazine $(n=1)$ & & & & & & \\
\hline \multirow[t]{2}{*}{ Newell et al, 2001} & $n=26$ & State institution & Antipsychotic dose & Post- & DISCUS score & Mean total DISCUS increased significantly & (1) \\
\hline & $69 \%$ o & & reduction by approx.. & discontinuation & & from baseline during antipsychotic & (3) \\
\hline \multirow[t]{13}{*}{ LE: 4} & Mean age $35 \mathrm{yrs}$ & USA & $25 \%$ every $2-4$ mths to & follow-up of 12 & & withdrawal (3.423 to $10.731, p<0.001)$ & (8) \\
\hline & ID: mild $4 \%$, moderate & & discontinuation & months & & before returning to baseline levels at follow- & (12) \\
\hline & $\begin{array}{l}20 \% \text {, severe } 46 \% \text {, } \\
\text { profound } 31 \%\end{array}$ & & & & & up (3.462). & \\
\hline & & & & & Tardive dyskinesia & Prevalence in group increased from $31 \%$ at & \\
\hline & No psychiatric & & & & (Kalachnik \& Sprague & baseline to $85 \%$ during antipsychotic & \\
\hline & comorbidities & & & & categorical definition) & withdrawal, and fell to $38 \%$ at follow-up & \\
\hline & Antipsychotics: & & & & & & \\
\hline & haloperidol $(n=9)$ & & & & & & \\
\hline & thioridazine $(n=9)$ & & & & & & \\
\hline & chlorpromazine $(n=3)$ & & & & & & \\
\hline & mosoridazine $(n=3)$ & & & & & & \\
\hline & loxapine $(n=1)$ & & & & & & \\
\hline & trifluperazine $(n=1)$ & & & & & & \\
\hline \multirow[t]{2}{*}{ Newell et al, 2002} & $n=20$ & State institution & Antipsychotic dose & Post- & Postural stability & Indices of postural stability changed & (1) \\
\hline & $75 \%$ ठ & & reduction by approx.. & discontinuation & & significantly over the course of medication & (3) \\
\hline \multirow[t]{6}{*}{ LE: 4} & Mean age 37 yrs & USA & $25 \%$ every $3 \mathrm{mths}$ to & follow-up of 12 & & withdrawal and tended to return to baseline & (4) \\
\hline & ID: severe-profound & & discontinuation & months & & levels at follow-up & (7) \\
\hline & $100 \%$ & & & & & & (8) \\
\hline & & & & & DISCUS & Mean total DISCUS increased significantly & (9) \\
\hline & No comorbidities & & & & & from baseline during antipsychotic & (12) \\
\hline & & & & & & withdrawal (3.52 to $11.10, p<0.01)$, before & \\
\hline
\end{tabular}




\begin{tabular}{|c|c|c|c|c|c|c|c|}
\hline & $\begin{array}{l}\text { Antipsychotics: } \\
\text { thioridazline }(n=7) \\
\text { haloperidol }(n=5) \\
\text { trifluoperazine }(n=3) \\
\text { loxapine }(n=3) \\
\text { chlorpromazine }(n=2)\end{array}$ & & & & & $\begin{array}{l}\text { returning to baseline levels at follow-up } \\
\text { (3.75). }\end{array}$ & \\
\hline Smith et al, 2002 & $\begin{array}{l}n=56 \\
48 \% \text { o }\end{array}$ & $\begin{array}{l}\text { 45\% hospital } \\
55 \% \text { community }\end{array}$ & & \multirow{5}{*}{$\begin{array}{l}6 \text { months (1 } \\
\text { month after } \\
\text { planned } \\
\text { discontinuation) }\end{array}$} & \multirow[t]{5}{*}{$\begin{array}{l}\text { Responsiveness to staff } \\
\text { interaction }\end{array}$} & \multirow{5}{*}{$\begin{array}{l}\text { No difference between group undergoing } \\
\text { antipsychotic reduction/discontinuation and } \\
\text { control group }\end{array}$} & $\begin{array}{l}\text { (1) } \\
\text { (2) }\end{array}$ \\
\hline LE: 2 & Mean age 43 yrs & & Intervention group & & & & (3) \\
\hline \multirow[t]{3}{*}{$\begin{array}{l}\text { Additional } \\
\text { reporting of } \\
\text { Ahmed et al, } 2000\end{array}$} & $\begin{array}{l}\text { ID: mild } 7 \% \text {, moderate } \\
30 \% \text {, severe } 26 \% \text {, } \\
\text { profound } 35 \%\end{array}$ & UK & $\begin{array}{l}\text { ( } n=36) \text { : reduction of } \\
\text { antipsychotic by } 25 \% \\
\text { monthly to } \\
\text { discontinuation }\end{array}$ & & & & (7) \\
\hline & $\begin{array}{l}\text { Comorbidities not } \\
\text { reported but none had } \\
\text { psychosis }\end{array}$ & & $\begin{array}{l}\text { Control group }(n=20) \text { : no } \\
\text { medication changes }\end{array}$ & & & & \\
\hline & $\begin{array}{l}\text { Antipsychotics: } \\
\text { Thioridazine }(n=18) \text {, } \\
\text { haloperidol }(n=13) \text {, } \\
\text { chlorpromazine }(n=8) \text {, } \\
\text { other ( } n=17)\end{array}$ & & & & & & \\
\hline \multirow[t]{4}{*}{$\begin{array}{l}\text { Janowsky et al, } \\
2006\end{array}$} & $\begin{array}{l}n=138 \\
\text { from a larger cohort }\end{array}$ & State institution & \multirow{4}{*}{$\begin{array}{l}\text { Medication review and } \\
\text { dose reduction } \\
\text { programme (not } \\
\text { according to a pre- } \\
\text { defined schedule) }\end{array}$} & \multirow[t]{2}{*}{3 months } & \multirow[t]{2}{*}{$\begin{array}{l}\text { Number discontinuing } \\
\text { antipsychotic medication }\end{array}$} & \multirow{2}{*}{$\begin{array}{l}83 / 138(60 \%) \text { discontinued antipsychotic } \\
\text { medication } \\
55 / 138(40 \%) \text { experienced behavioural } \\
\text { disturbance requiring re-prescribing }\end{array}$} & $\begin{array}{l}(1) \\
(8)\end{array}$ \\
\hline & $\begin{array}{l}(n=151): \\
60 \%{ }^{\lambda} \\
\text { Mean age } 48 \text { yrs }\end{array}$ & USA & & & & & $\begin{array}{l}(9) \\
(10)\end{array}$ \\
\hline & $\begin{array}{l}\text { ID: severe-profound } \\
100 \%\end{array}$ & & & \multirow[t]{2}{*}{ Ave 10 years } & \multirow[t]{2}{*}{$\begin{array}{l}\text { Number discontinuing } \\
\text { antipsychotic medication }\end{array}$} & \multirow{2}{*}{$\begin{array}{l}74 / 138(54 \%) \text { discontinued antipsychotic } \\
\text { medication } \\
64 / 138(46 \%) \text { could not discontinue } \\
\text { antipsychotic medication }\end{array}$} & \\
\hline & $\begin{array}{l}\text { Psychiatric } \\
\text { comorbidities incl. } \\
\text { bipolar disorder, } \\
\text { autism, stereotyped } \\
\text { movements with self- } \\
\text { injury, intermittent } \\
\text { explosive disorder, } \\
\text { mood disorder, } \\
\text { obsessive-compulsive }\end{array}$ & & & & & & \\
\hline
\end{tabular}




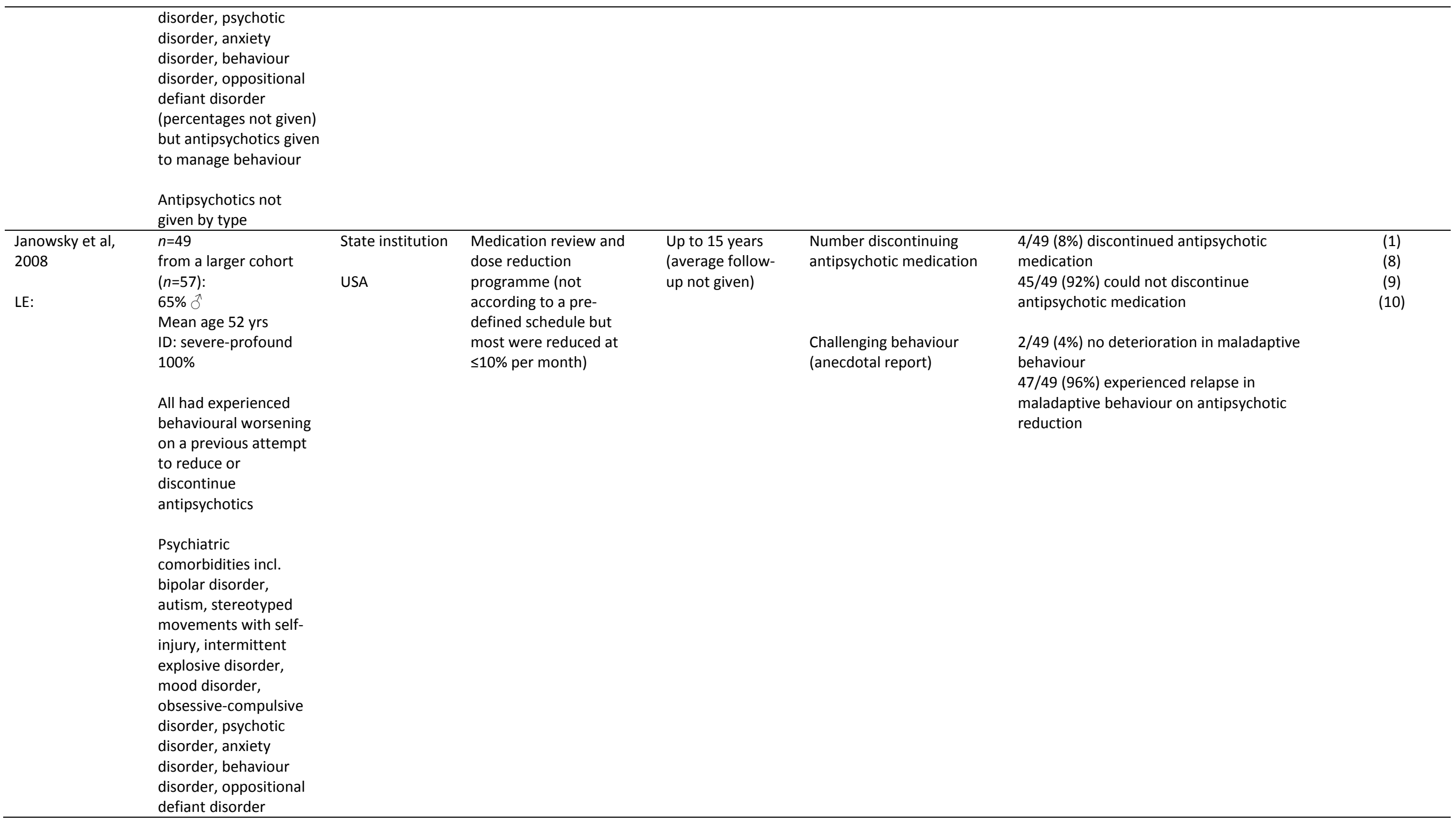




\begin{tabular}{|c|c|c|c|c|c|c|c|}
\hline & $\begin{array}{l}\text { (percentages not given) } \\
\text { but antipsychotics given } \\
\text { to manage behaviour } \\
\text { Antipsychotics (larger } \\
\text { group): } \\
\text { haloperidol }(n=24) \text {, } \\
\text { thioridazine }(n=20) \text {, } \\
\text { chlorpromazine }(n=7) \text {, } \\
\text { thiothixine }(n=5) \text {, } \\
\text { loxapine }(n=1)\end{array}$ & & & & & & \\
\hline $\begin{array}{l}\text { deKuijper et al, } \\
2013 \\
\text { LE: } 4 \\
\text { Additional } \\
\text { reporting of } \\
\text { deKuijper et al, } \\
2014\end{array}$ & 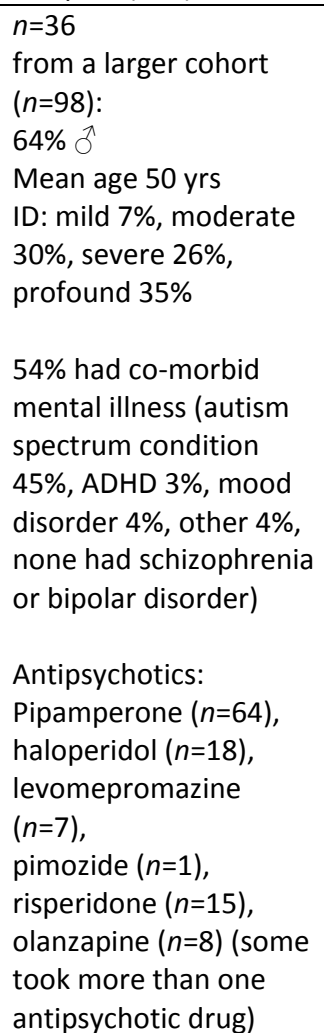 & $\begin{array}{l}\text { Residential care } \\
\text { centres ( } 74 \%) \\
\text { and community } \\
\text { settings (26\%) } \\
\text { Netherlands }\end{array}$ & $\begin{array}{l}\text { Planned reduction of } \\
\text { antipsychotic by } 12.5 \% \\
\text { every } 2 \text { or } 4 \text { weeks } \\
\text { (random allocation to } \\
\text { reduction schedule in } 1: 1 \\
\text { ratio) } \\
\text { Results of those achieving } \\
\text { antipsychotic } \\
\text { discontinuation }(n=36)\end{array}$ & $\begin{array}{l}26 \text { or } 40 \text { weeks } \\
\text { (12 weeks after } \\
\text { discontinuation, } \\
\text { depending on } \\
\text { reduction } \\
\text { schedule ( } n=21 \text { on } \\
\text { faster reduction } \\
\text { schedule, } n=15 \text { on } \\
\text { slower reduction } \\
\text { schedule) }\end{array}$ & $\begin{array}{l}\text { Waist circumference } \\
\text { Weight } \\
\text { BMI } \\
\text { Systolic BP } \\
\text { Diastolic BP } \\
\text { Plasma triglycerides } \\
\text { Plasma HDL } \\
\text { Plasma glucose }\end{array}$ & $\begin{array}{l}\text { Mean change }-4.4 \mathrm{~cm}(p<0.001) \\
\text { Mean change }-3.5 \mathrm{~kg}(p=0.02) \\
\text { Mean change }-1.41 \mathrm{~kg} / \mathrm{m}^{2}(p=0.006) \\
\text { Mean change }-7.1 \mathrm{mmHg}(p=0.02) \\
\text { Mean change }-4.3 \mathrm{mmHg}(p=\mathrm{NS}) \\
\text { Mean change }+0.05 \mathrm{mmol} / \mathrm{L}(p=\mathrm{NS}) \\
\text { Mean change }+0.04 \mathrm{mmol} / \mathrm{L}(p=\mathrm{NS}) \\
\text { Mean change }-0.09 \mathrm{mmol} / \mathrm{L}(p=\mathrm{NS})\end{array}$ & $\begin{array}{c}(1) \\
(3) \\
(7) \\
(8) \\
(12)\end{array}$ \\
\hline
\end{tabular}




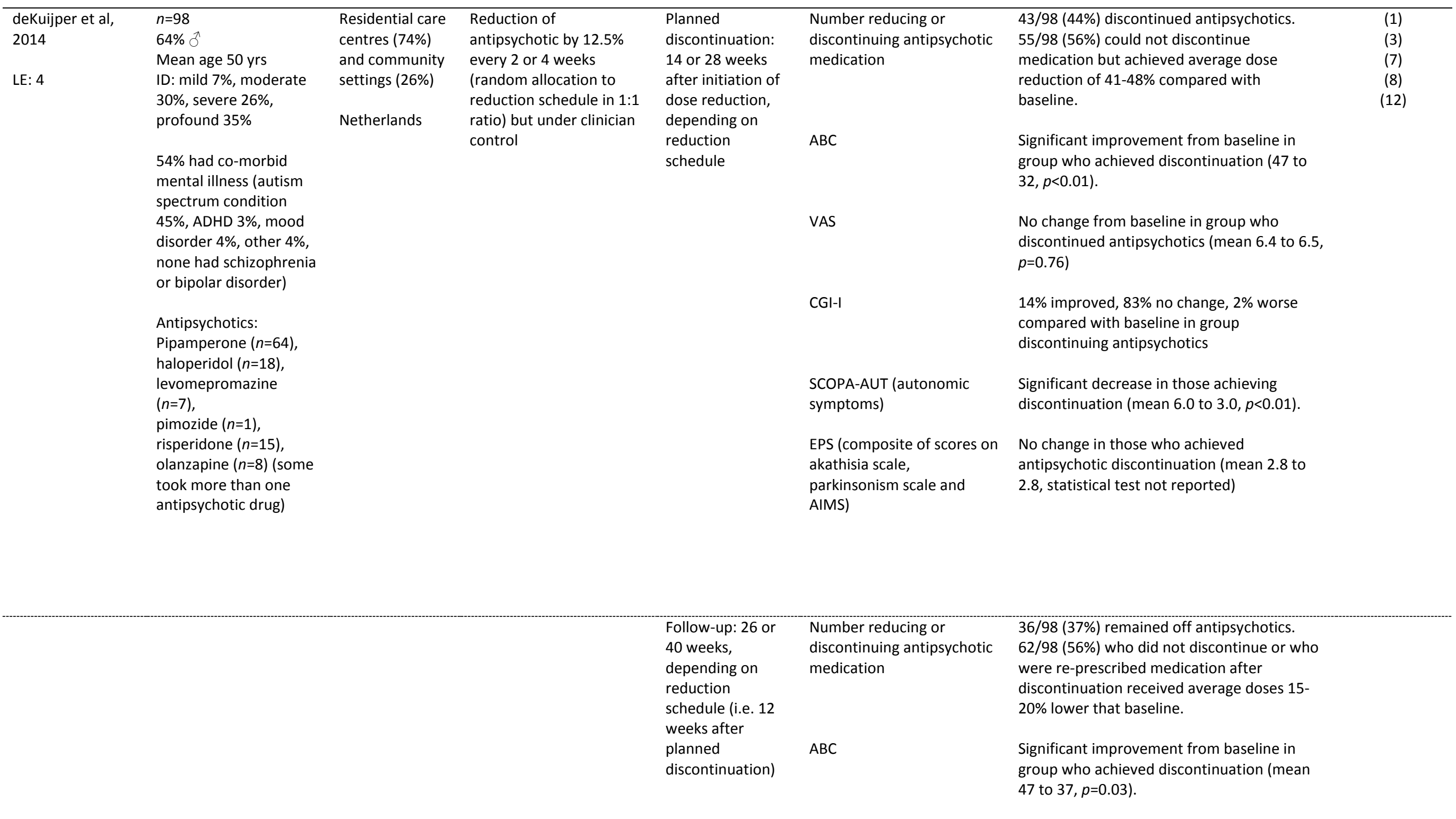


No change from baseline in group who

discontinued antipsychotics (mean 6.4 to 6.5 ,

$p=0.76$ )

CGI-I

$31 \%$ improved, $64 \%$ no change, $5 \%$ worse

compared with baseline in group

discontinuing antipsychotics

SCOPA-AUT (autonomic

symptoms)

Significant decrease in those who achieved

EPS (composite of scores on

discontinut

akathisia scale,

Slight increase in those who achieved

parkinsonism scale and

antipsychotic discontinuation (mean 2.8 to

AIMS)

3.0, statistical test not reported). 
ABC, aberrant behaviour checklist; AIMS, abnormal involuntary movement scale; BMI, body mass index; BP, blood pressure; DISCUS, dyskinesia identification system: condensed user scale; CGI-I, clinical global impression-improvement scale; ENT, ear, nose and throat; EPS, extrapyramidal symptoms; HDL, high density lipoprotein; ID, intellectual disability; RCT, randomised controlled trial; SCOPA-AUT, scale outcomes Parkinson's disease - automonic symptoms; TD, tardive dyskinesia; VAS, visual analogue scale

Table 1 Summary of included studies

\section{Key to biases and limitations (in order of appearance in table):}

(1) Selection bias

(2) Control group inadequately matched

(3) Lack of blinding

(4) Use of unvalidated measures/non-standard assessment tools

(5) Small sample size (<10 undergoing intervention)

(6) Possible practise effect

(7) Statistics or statistical tests inadequately reported or inappropriate

(8) Institutional setting

(9) Missing baseline information

(10) Intervention poorly defined

(11) Retrospective report/possible recall bias

(12) Lack of control group

(13) Selective reporting/incomplete outcome data 


\begin{tabular}{|c|c|c|c|c|c|c|c|}
\hline Study & $n$ & Follow-up & $\begin{array}{l}\text { Antipsychotic } \\
\text { discontinued at } \\
\text { follow-up }\end{array}$ & $\begin{array}{l}\text { Antipsychotic } \\
\text { discontinued } \\
\text { or reduced at } \\
\text { follow-up }\end{array}$ & $\begin{array}{l}\text { Antipsychotic } \\
\text { reduced at } \\
\text { follow-up }\end{array}$ & $\begin{array}{l}\text { Antipsychotic } \\
\text { reduced or no } \\
\text { change at } \\
\text { follow-up }\end{array}$ & $\begin{array}{l}\text { Antipsychotic } \\
\text { no change or } \\
\text { increased at } \\
\text { follow-up }\end{array}$ \\
\hline \multirow[t]{2}{*}{ Hancock $^{40}$} & 42 & 5 yrs & $10 / 42(24 \%)$ & - & - & $32 / 42(76 \%)$ & - \\
\hline & & $10 \mathrm{yrs}$ & $31 / 42(74 \%)$ & - & - & $11 / 42(26 \%)$ & - \\
\hline Lepler $^{41}$ & 6 & 4 yrs & $1 / 6(17 \%)$ & - & $5 / 6(83 \%)$ & - & - \\
\hline Spreat $^{42}$ & 86 & $1 \mathrm{yr}$ & - & $40(47 \%)$ & - & $46 / 86(53 \%)$ & - \\
\hline Wigal $^{38}$ & 245 & $1 \mathrm{yr}$ & $141 / 245(58 \%)$ & - & - & $104 / 245(42 \%)$ & - \\
\hline Jauernig $^{43}$ & 25 & 2 yrs & $3 / 25(12 \%)$ & - & $19 / 25(76 \%)$ & - & $3 / 25(12 \%)$ \\
\hline Branford ${ }^{44}$ & 123 & $1 \mathrm{yr}$ & $31 / 123(25 \%)$ & - & $56 / 123(46 \%)$ & - & $36 / 123(29 \%)$ \\
\hline Ahmed $^{32}$ & 56 & 6 mths & $12 / 36(33 \%)$ & - & $7 / 36(19 \%)$ & - & $17 / 36(47 \%)$ \\
\hline \multirow[t]{2}{*}{$J^{2}$ anowsky ${ }^{45}$} & 138 & 3 mths & $83 / 138(60 \%)$ & - & - & $55 / 138(40 \%)$ & - \\
\hline & & 10 yrs & $74 / 138(54 \%)$ & - & - & $64 / 138(46 \%)$ & - \\
\hline Janowsky $^{46}$ & 49 & Up to 15 yrs & $2 / 49(4 \%)$ & & & $47 / 49(96 \%)$ & \\
\hline \multirow[t]{2}{*}{ deKuijper $^{47}$} & 51 & 26 wks & $21 / 51(41 \%)$ & - & - & $30 / 51$ (59\%) & - \\
\hline & 47 & 40 wks & $15 / 47(32 \%)$ & - & - & $32 / 47(68 \%)$ & - \\
\hline
\end{tabular}

Table 2-Outcome of interventions to reduce or discontinue antipsychotic medication 


\section{Demographic factors}

Male sex ${ }^{47}$

Female sex ${ }^{40}$

\section{Clinical factors}

Higher baseline antipsychotic dose $\mathrm{e}^{47,48,57,58}$

Higher baseline behavioural symptoms $\mathrm{s}^{47,48,57}$

Lower baseline behavioural symptoms ${ }^{48}$

Higher baseline extrapyramidal symptoms ${ }^{47}$

Higher baseline psychopathology $y^{5,59}$

Previous unsuccessful antipsychotic withdrawal attempt ${ }^{46}$

Absence of co-administration of other psychoactive medication ${ }^{39,} 59$

\section{Setting/environmental factors}

More restrictive environments ${ }^{32}$

Lower staffing levels and training ${ }^{32}$

Table 3 Factors shown to be associated with unsuccessful attempts to reduce or discontinue antipsychotic medication in people with ID taking antipsychotics for challenging behaviour 
- High quality studies that investigate the feasibility of reduction or discontinuation of antipsychotics used for challenging behaviour in people with intellectual disability are needed.

- Baseline characteristics of study participants should be well-defined and include screening for co-morbid mental illness using standardised instruments (such as the PAS-ADD) or adapted diagnostic criterial (such as the DC-LD).

- To be useful in guiding management decisions, studies should be adequately powered to elucidate environmental and individual characteristics that are associated with successful and unsuccessful attempts to reduce or discontinue antipsychotic medication.

- Although patient and caregiver attitude towards antipsychotic medication for challenging behaviour and concordance with treatment plans quite clearly influence their success, these were not mentioned in included studies, and should be investigated further.

- The economic impact and change in resource use resulting from antipsychotic reduction or discontinuation for challenging behaviour is likely to be complex and will require the balancing of short-term risks (e.g. management of behavioural deterioration) against potential longer-term savings (e.g. in prescription costs and managing long-term adverse side-effects).

- Novel or pragmatic study designs, possibly using routinely-collected health data, might be appropriate for further investigating this topic.

Panel 2 Future research directions 


\section{Appendix A - full list of search terms}

Medline search terms (conducted on 27/03/2016)

\begin{tabular}{|c|c|c|}
\hline $\begin{array}{l}\text { Terms for intellectual } \\
\text { disability (title or abstract) }\end{array}$ & $\begin{array}{l}\text { Terms for anti-psychotic (title } \\
\text { or abstract) }\end{array}$ & $\begin{array}{l}\text { Terms for reduction or } \\
\text { discontinuation (title or abstract) }\end{array}$ \\
\hline Intellectual* disab* & Anti\$psychotic* & Withdraw* \\
\hline Intellectual* impair* & Neuroleptic* & Discontinu* \\
\hline Intellectual* retard* & Major tranquil*i*er* & Stop* \\
\hline Intellectual* handicap* & Dopamine antagonist & Remov* \\
\hline Intellectual* subnormal* & Phenothiazine* & Reduc* \\
\hline Intellectual* deficien* & Butyrophenone* & Minimi* \\
\hline Learning disab* & Thioxanthene* & Cessation \\
\hline Learning impair* & Diphenylbutylpiperidine* & Taper* \\
\hline Learning retard* & Benperidol & \\
\hline Learning handicap* & Chlorpromazine & \\
\hline Learning subnormal* & Droperidol & \\
\hline Learning deficien* & Flupent*ixol & \\
\hline Mental* disab* & Haloperidol & \\
\hline Mental* impair* & Levomepromazine & \\
\hline Mental* retard* & Peric*azine & \\
\hline Mental* handicap* & Perphenazine & \\
\hline Mental* subnormal* & Pimozide & \\
\hline Mental* deficien* & Prochlorperazine & \\
\hline Developmental* disab* & Promazine & \\
\hline Developmental* impair* & Sulpiride & \\
\hline Developmental* retard* & Trifluoperazine & \\
\hline Developmental* handicap* & Zuclopent*ixol & \\
\hline $\begin{array}{l}\text { Developmental* } \\
\text { subnormal* }\end{array}$ & Amisulp*ride & \\
\hline Developmental* deficien* & Aripiprazole & \\
\hline $\begin{array}{l}\text { Neurodevelopmental* } \\
\text { disab* }\end{array}$ & Asenapine & \\
\hline $\begin{array}{l}\text { Neurodevelopmental* } \\
\text { impair* }\end{array}$ & Clozapine & \\
\hline $\begin{array}{l}\text { Neurodevelopmental* } \\
\text { retard* }\end{array}$ & Lurasidone & \\
\hline $\begin{array}{l}\text { Neurodevelopmental* } \\
\text { handicap* }\end{array}$ & Olanzapine & \\
\hline $\begin{array}{l}\text { Neurodevelopmental* } \\
\text { subnormal* }\end{array}$ & Paliperidone & \\
\hline \multirow{3}{*}{$\begin{array}{l}\text { Neurodevelopmental* } \\
\text { deficien* }\end{array}$} & Quetiapine & \\
\hline & Risperidone & \\
\hline & Thioridazine & \\
\hline \multicolumn{3}{|l|}{ MeSH headings } \\
\hline Intellectual Disability & Antipsychotic Agents & Substance Withdrawal Syndrome \\
\hline Mentally Disabled Persons & Dopamine Antagonists & \\
\hline
\end{tabular}


PsycINFO search terms (conducted on 27/03/2016)

\begin{tabular}{|c|c|c|}
\hline $\begin{array}{l}\text { Terms for intellectual } \\
\text { disability (title or abstract) }\end{array}$ & $\begin{array}{l}\text { Terms for anti-psychotic (title } \\
\text { or abstract) }\end{array}$ & $\begin{array}{l}\text { Terms for reduction or } \\
\text { discontinuation (title or abstract) }\end{array}$ \\
\hline Intellectual* disab* & Anti-psychotic* & Withdraw* \\
\hline Intellectual* impair* & Antipsychotic* & Discontinu* \\
\hline Intellectual* retard* & Neuroleptic* & Stop* \\
\hline Intellectual* handicap* & Major tranquil*i*er* & Remov* \\
\hline Intellectual* subnormal* & Dopamine antagonist & Reduc* \\
\hline Intellectual* deficien* & Phenothiazine* & Minimi* \\
\hline Learning disab* & Butyrophenone* & Cessation \\
\hline Learning impair* & Thioxanthene* & Taper* \\
\hline Learning retard* & Diphenylbutylpiperidine* & \\
\hline Learning handicap* & Benperidol & \\
\hline Learning subnormal* & Chlorpromazine & \\
\hline Learning deficien* & Droperidol & \\
\hline Mental* disab* & Flupent*ixol & \\
\hline Mental* impair* & Haloperidol & \\
\hline Mental* retard* & Levomepromazine & \\
\hline Mental* handicap* & Peric*azine & \\
\hline Mental* subnormal* & Perphenazine & \\
\hline Mental* deficien* & Pimozide & \\
\hline Developmental* disab* & Prochlorperazine & \\
\hline Developmental* impair* & Promazine & \\
\hline Developmental* retard* & Sulpiride & \\
\hline Developmental* handicap* & Trifluoperazine & \\
\hline $\begin{array}{l}\text { Developmental* } \\
\text { subnormal* }\end{array}$ & Zuclopent*ixol & \\
\hline Developmental* deficien* & Amisulp*ride & \\
\hline $\begin{array}{l}\text { Neurodevelopmental* } \\
\text { disab* }\end{array}$ & Aripiprazole & \\
\hline $\begin{array}{l}\text { Neurodevelopmental* } \\
\text { impair* }\end{array}$ & Asenapine & \\
\hline $\begin{array}{l}\text { Neurodevelopmental* } \\
\text { retard* }\end{array}$ & Clozapine & \\
\hline $\begin{array}{l}\text { Neurodevelopmental* } \\
\text { handicap* }\end{array}$ & Lurasidone & \\
\hline $\begin{array}{l}\text { Neurodevelopmental* } \\
\text { subnormal* }\end{array}$ & Olanzapine & \\
\hline \multirow[t]{4}{*}{$\begin{array}{l}\text { Neurodevelopmental* } \\
\text { deficien* }\end{array}$} & Paliperidone & \\
\hline & Quetiapine & \\
\hline & Risperidone & \\
\hline & Thioridazine & \\
\hline \multicolumn{3}{|l|}{ MeSH headings } \\
\hline $\begin{array}{l}\text { Intellectual development } \\
\text { disorder }\end{array}$ & Neuroleptic drugs & Drug withdrawal \\
\hline Developmental disabilities & Dopamine antagonists & \\
\hline
\end{tabular}


EMBASE search terms (conducted on 28/03/2016)

\begin{tabular}{|c|c|c|}
\hline $\begin{array}{l}\text { Terms for intellectual } \\
\text { disability (title or abstract) }\end{array}$ & $\begin{array}{l}\text { Terms for anti-psychotic (title } \\
\text { or abstract) }\end{array}$ & $\begin{array}{l}\text { Terms for reduction or } \\
\text { discontinuation (title or abstract) }\end{array}$ \\
\hline Intellectual* disab* & Anti-psychotic* & Withdraw* \\
\hline Intellectual* impair* & Antipsychotic* & Discontinu* \\
\hline Intellectual* retard* & Neuroleptic* & Stop* \\
\hline Intellectual* handicap* & Major tranquil*i*er* & Remov* \\
\hline Intellectual* subnormal* & Dopamine antagonist & Reduc* \\
\hline Intellectual* deficien* & Phenothiazine* & Minimi* \\
\hline Learning disab* & Butyrophenone* & Cessation \\
\hline Learning impair* & Thioxanthene* & Taper* \\
\hline Learning retard* & Diphenylbutylpiperidine* & \\
\hline Learning handicap* & Benperidol & \\
\hline Learning subnormal* & Chlorpromazine & \\
\hline Learning deficien* & Droperidol & \\
\hline Mental* disab* & Flupent*ixol & \\
\hline Mental* impair* & Haloperidol & \\
\hline Mental* retard* & Levomepromazine & \\
\hline Mental* handicap* & Peric*azine & \\
\hline Mental* subnormal* & Perphenazine & \\
\hline Mental* deficien* & Pimozide & \\
\hline Developmental* disab* & Prochlorperazine & \\
\hline Developmental* impair* & Promazine & \\
\hline Developmental* retard* & Sulpiride & \\
\hline Developmental* handicap* & Trifluoperazine & \\
\hline $\begin{array}{l}\text { Developmental* } \\
\text { subnormal* }\end{array}$ & Zuclopent*ixol & \\
\hline Developmental* deficien* & Amisulp*ride & \\
\hline $\begin{array}{l}\text { Neurodevelopmental* } \\
\text { disab* }\end{array}$ & Aripiprazole & \\
\hline $\begin{array}{l}\text { Neurodevelopmental* } \\
\text { impair* }\end{array}$ & Asenapine & \\
\hline $\begin{array}{l}\text { Neurodevelopmental* } \\
\text { retard* }\end{array}$ & Clozapine & \\
\hline $\begin{array}{l}\text { Neurodevelopmental* } \\
\text { handicap* }\end{array}$ & Lurasidone & \\
\hline $\begin{array}{l}\text { Neurodevelopmental* } \\
\text { subnormal* }\end{array}$ & Olanzapine & \\
\hline \multirow[t]{4}{*}{$\begin{array}{l}\text { Neurodevelopmental* } \\
\text { deficien* }\end{array}$} & Paliperidone & \\
\hline & Quetiapine & \\
\hline & Risperidone & \\
\hline & Thioridazine & \\
\hline \multicolumn{3}{|l|}{ MeSH headings } \\
\hline intellectual impairment & neuroleptic agent & drug withdrawal \\
\hline mental deficiency & $\begin{array}{l}\text { dopamine receptor blocking } \\
\text { agent }\end{array}$ & \\
\hline
\end{tabular}


CINAHL Plus search terms (conducted on 28/03/2016)

\begin{tabular}{|c|c|c|}
\hline $\begin{array}{l}\text { Terms for intellectual } \\
\text { disability }\end{array}$ & Terms for anti-psychotic & $\begin{array}{l}\text { Terms for reduction or } \\
\text { discontinuation }\end{array}$ \\
\hline Intellectual* disab* & Anti-psychotic* & Withdraw* \\
\hline Intellectual* impair* & Antipsychotic* & Discontinu* \\
\hline Intellectual* retard* & Neuroleptic* & Stop* \\
\hline Intellectual* handicap* & Major tranquiliser* & Remov* \\
\hline Intellectual* subnormal* & Major tranquilliser* & Reduc* \\
\hline Intellectual* deficien* & Major tranquilizer* & Cessation \\
\hline Learning disab* & Major tranqillizer* & Taper* \\
\hline Learning impair* & Dopamine antagonist* & \\
\hline Learning retard* & Phenothiazine* & \\
\hline Learning handicap* & Butyrophenone* & \\
\hline Learning subnormal* & Thioxanthene* & \\
\hline Learning deficien* & Diphenylbutylpiperidine* & \\
\hline Mental* disab* & Benperidol & \\
\hline Mental* impair* & Chlorpromazine & \\
\hline Mental* retard* & Droperidol & \\
\hline Mental* handicap* & Flupenthixol & \\
\hline Mental* subnormal* & Flupentixol & \\
\hline Mental* deficien* & Haloperidol & \\
\hline Developmental* disab* & Levomepromazine & \\
\hline Developmental* impair* & Periciazine & \\
\hline Developmental* retard* & Pericyazine & \\
\hline Developmental* handicap* & Perphenazine & \\
\hline $\begin{array}{l}\text { Developmental* } \\
\text { subnormal* }\end{array}$ & Pimozide & \\
\hline Developmental* deficien* & Prochlorperazine & \\
\hline $\begin{array}{l}\text { Neurodevelopmental* } \\
\text { disab* }\end{array}$ & Promazine & \\
\hline $\begin{array}{l}\text { Neurodevelopmental* } \\
\text { impair* }\end{array}$ & Sulpiride & \\
\hline $\begin{array}{l}\text { Neurodevelopmental* } \\
\text { retard* }\end{array}$ & Trifluoperazine & \\
\hline $\begin{array}{l}\text { Neurodevelopmental* } \\
\text { handicap* }\end{array}$ & Zuclopenthixol & \\
\hline $\begin{array}{l}\text { Neurodevelopmental* } \\
\text { subnormal* }\end{array}$ & Zuclopentixol & \\
\hline \multirow{10}{*}{$\begin{array}{l}\text { Neurodevelopmental* } \\
\text { deficien* }\end{array}$} & Amisulpride & \\
\hline & Amisulpiride & \\
\hline & Aripiprazole & \\
\hline & Asenapine & \\
\hline & Clozapine & \\
\hline & Lurasidone & \\
\hline & Olanzapine & \\
\hline & Paliperidone & \\
\hline & Quetiapine & \\
\hline & Risperidone & \\
\hline
\end{tabular}




\begin{tabular}{|l|l|l|}
\hline \multicolumn{2}{|l|}{ Thioridazine } & \\
\hline CINAHL headings & Dopamine antagonists & Substance withdrawal syndrome \\
\hline Intellectual disability & Antipsychotic agents & $\begin{array}{l}\text { Substance withdrawal, } \\
\text { controlled }\end{array}$ \\
\hline Mentally disabled persons & $\begin{array}{l}\text { Antipsychotic agents, } \\
\text { phenothiazine }\end{array}$ \\
\hline & $\begin{array}{l}\text { Antipsychotic agents, } \\
\text { butyrophenone }\end{array}$ & \\
\hline
\end{tabular}

Systematic review - Cochrane (conducted on 28/03/16)

\begin{tabular}{|c|c|c|}
\hline $\begin{array}{l}\text { Terms for intellectual } \\
\text { disability }\end{array}$ & Terms for anti-psychotic & $\begin{array}{l}\text { Terms for reduction or } \\
\text { discontinuation }\end{array}$ \\
\hline \multirow[t]{8}{*}{$\begin{array}{l}\text { (Intellectual* OR learning* } \\
\text { OR mental* OR } \\
\text { developmental* OR } \\
\text { neurodevelopmental*) } \\
\text { NEXT (disab* OR impair* OR } \\
\text { retard* OR handicap* OR } \\
\text { subnormal* OR deficien*) } \\
\end{array}$} & Anti-psychotic* & Withdraw* \\
\hline & Neuroleptic* & Discontinu* \\
\hline & "major tranquiliser" & Stop* \\
\hline & "Dopamine antagonist" & Remov* \\
\hline & & Reduc* \\
\hline & & Minimi* \\
\hline & & Cessation \\
\hline & & Taper* \\
\hline \multicolumn{3}{|l|}{ MeSH terms } \\
\hline Intellectual disability & Dopamine antagonists & Substance withdrawal syndrome \\
\hline Mentally disabled persons & Antipsychotic agents & \\
\hline
\end{tabular}




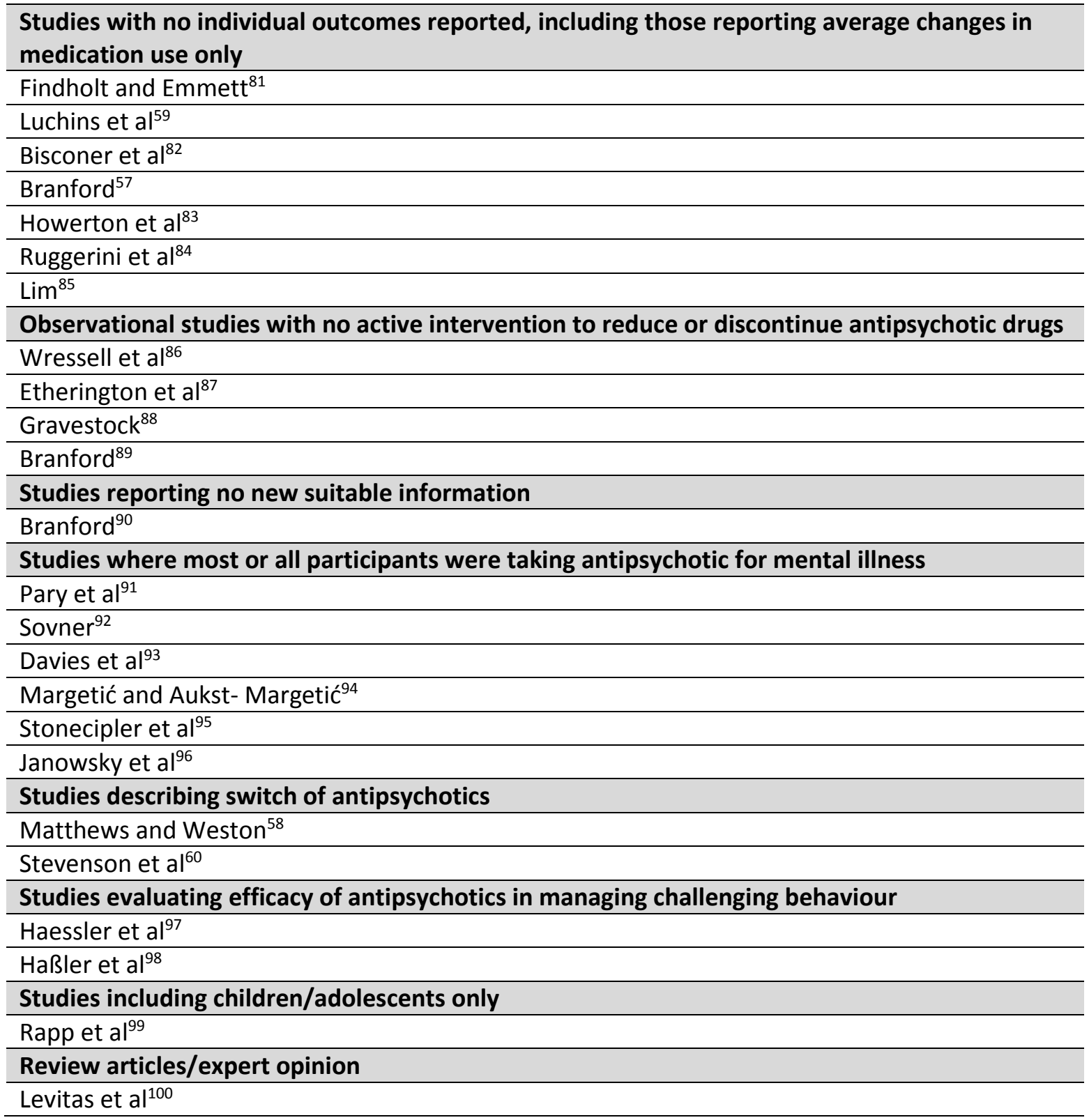


Appendix C - Behavioural outcome measures used in included studies

\begin{tabular}{ll}
\hline Method/instrument & Description \\
\hline $\begin{array}{l}\text { Aberrant behaviour } \\
\text { checklist (ABC) }\end{array}$ & $\begin{array}{l}58 \text { item carer-rated scale measuring range of behavioural disturbances in } 5 \text { sub- } \\
\text { scales. Sensitive to changes in behaviour secondary to medication change }\end{array}$ \\
\hline $\begin{array}{l}\text { Visual analogue scale } \\
\text { (VAS) }\end{array}$ & $\begin{array}{l}\text { Target behaviour(s) rated by caregiver between } 0 \text { (severe) and } 10 \text { (mild) on a } \\
\text { generic scale used to quantify subjective experience }\end{array}$ \\
\hline Direct observation & $\begin{array}{l}\text { Formal categorisation of behaviour according to pre-defined groups in discrete } \\
\text { time periods during which the behaviour of the participant is observed }\end{array}$ \\
\hline Descriptive report & $\begin{array}{l}\text { Any statement(s) where any aspect of the behaviour of individuals or of the } \\
\text { group is described }\end{array}$ \\
\hline
\end{tabular}

